\title{
Green catalytic processing of native and organosolv lignins
}

\author{
B.N. Kuznetsov ${ }^{1,2}$, N.V Chesnokov ${ }^{1}$, I.G. Sudakova ${ }^{1}$, \\ N.V. Garyntseva ${ }^{1}$, S.A. Kuznetsova ${ }^{1,2}$, Yu. N. Malyar ${ }^{1,2}$, V.A. Yakovlev ${ }^{3}$, L. Djakovitch ${ }^{4}$ \\ ${ }^{1}$ Institute of Chemistry and Chemical Technology SB RAS, FRC KSC SB RAS \\ Krasnoyarsk, 660036, Akademgorodok, 50-24, Russia \\ *e-mail: bnk@icct.ru,Fax/Tel+7(391)249-48-94 \\ ${ }^{2}$ Siberian Federal University, Krasnoyarsk, 660041, Svobodny prospect, 79, Russia \\ ${ }^{3}$ Boreskov Institute of Catalysis, SB RAS, Novosibirsk, 630090, pr. Ak. Lavrentieva, 5,Russia \\ ${ }^{4}$ IRCELYON, 2 avenue Albert Einstein, F-69626 Villeurbanne Cedex, Lyon, France
}

\begin{abstract}
Two ways of catalytic depolymerization of native and isolated wood lignins are described: the peroxide delignification of hardwood (aspen, birch) and softwood (abies) in the medium of acetic acid - water over $\mathrm{TiO}_{2}$ catalyst and the thermal dissolution of organosolv lignins (ethanol-lignin and acetone-lignin) in supercritical alcohols (ethanol and butanol) over solid Ni-containing catalysts.

The catalyst $\mathrm{TiO}_{2}$ in rutile modification has the higher activity in wood peroxide delignification at $100^{\circ} \mathrm{C}$ as compared to $\mathrm{TiO}_{2}$ in anatase modification. The results of kinetic studies and optimization of the processes of peroxide depolymerization of hardwood (aspen, birch) and softwood (abies) lignins in the medium of acetic acid - water over catalyst $\mathrm{TiO}_{2}$ (rutile) at mild conditions $\left(\leq 100^{\circ} \mathrm{C}\right.$, atmospheric pressure) are compared. The catalyst $\mathrm{TiO}_{2}$ initiates the formation of $\mathrm{OH}^{\bullet}$ and $\mathrm{OOH}^{\bullet}$ radicals from $\mathrm{H}_{2} \mathrm{O}_{2}$ which promote the oxidative fragmentation of wood lignin. In this case, the peroxide depolymerization of softwood lignin, constructed from phenylpropane units of guaiacyl-type proceeds more difficult than the hardwood lignins, mainly containing syringyl-type units.

The solid and soluble products of peroxide catalytic delignification of wood under the optimized conditions were studied by FTIR, XRD, GC-MS and chemical methods. Regardless of the nature of wood the cellulosic products have a structure similar to microcrystalline cellulose. The soluble products mainly consist of monosaccharides and organic acids. Aromatic compounds are present only in a low amount which indicates the oxidative degradation of aromatic rings of lignin phenylpropane units under the used conditions of wood catalytic delignification.
\end{abstract}

The processes of thermal dissolution of acetone-lignin and ethanol-lignin from aspenwood in supercritical ethanol and butanol over Ni-containing catalyst $\left(\mathrm{NiCu} / \mathrm{SiO}_{2}\right.$, 
$\mathrm{NiCuMo} / \mathrm{SiO}_{2}$ ) are compared. The composition, structure and thermal properties of organosolv lignins were studied with the use of FTIR, GPC, ${ }^{1} \mathrm{H}-{ }^{13} \mathrm{C}$ HSQC NMR, DTA and elemental analysis.

The influence of a composition of Ni-containing catalyst on the thermal conversion in supercritical butanol and ethanol of ethanol-lignin and acetone-lignin was established. The highest conversion of lignins (to 93\% wt.) in supercritical alcohols and the highest yield of liquid products (to $90 \%$ wt.) were achieved at $300{ }^{\circ} \mathrm{C}$ in the presence of catalyst $\mathrm{NiCuMo} / \mathrm{SiO}_{2}$.

Scheme of green biorefinery of wood based on the use of non-toxic and low-toxic reagents $\left(\mathrm{H}_{2} \mathrm{O}_{2}, \mathrm{H}_{2} \mathrm{O}\right.$, acetic acid, ethanol, butanol) and solid catalysts $\left(\mathrm{TiO}_{2}, \mathrm{NiCuMo} / \mathrm{SiO}_{2}\right)$ is suggested.

Keywords: lignin, depolymerization, catalysts, bio-liquids.

\section{Introduction}

Wood biomass is constructed from polysaccharides and lignin [1]. The lignin content depends on the type of tree: about $28 \%$ for softwood and $20 \%$ for hardwood. The cellulose content is approximately $45 \%$ in the wood of both types, while the hemicelluloses content is roughly $17 \%$ in softwoods and $25 \%$ in hardwoods. Lignin is a polymer of aromatic nature [2]. The principal monomer for softwood lignins is coniferyl alcohol. Hardwood lignins have two main monomers: coniferyl and sinapyl alcohols. The aromatic rings in lignins are presented by guaiacyl units with the one aryl- $\mathrm{OCH}_{3}$ group, which derived from coniferyl alcohol, by syringyl units with the two aryl- $\mathrm{OCH}_{3}$ groups, which derived from sinapyl alcohols and by phydroxyphenyl units without the $\mathrm{OCH}_{3}$-groups, which derived from p-coumaryl alcohol.

The huge amounts of waste lignin are produced by pulp and hydrolysis plants. But the high-tech methods of lignin valorization are lacking to date. The variable composition and structure of native and technical lignins complicate the choice of their utilization strategy.

With its unique structure and chemical properties a wide variety of bulk and fine chemicals, particularly aromatic and phenolic compounds are potentially obtainable from lignin. At present the different processes are used for lignin conversion: pyrolysis, catalytic hydrogenation, catalytic oxidation, alkaline depolymerization in supercritical fluids [3-5].

The studies, directed on catalytic processing of biomass and lignin into biofuels and chemicals are intensified in the last decade [4-7]. Application of catalysts allows to speed up the reactions of lignin depolymerization and to increase the yield of liquid products [8-11]. 
Promising directions of lignocellulosic biomass processing are connected with the use of solid catalysts which have a number of technological advantages in comparison with the dissolved catalytic systems [12-14].

Catalysts based on noble metals ( $\mathrm{Pd}, \mathrm{Ru}, \mathrm{Pt})$ and on the less expensive metals (Ni, Mo, etc.) supported on $\mathrm{Al}_{2} \mathrm{O}_{3}, \mathrm{SiO}_{2}$ and carbon carries are used in the different processes of lignin valorization $[8,15-16]$. In particular, the catalyst Ni/C shows the comparable with catalysts $\mathrm{Pt} / \mathrm{C}$, $\mathrm{Pd} / \mathrm{C}, \mathrm{Ru} / \mathrm{C}$ activity in organosolv lignin depolymerization in supercritical butanol with obtaining of alcylated phenols [17]. In alcohol medium the catalyst $\mathrm{Ni} / \mathrm{C}$ is active in the rupture of $\beta-\mathrm{O}-4$ bonds between lignin structural fragments with the formation of monomeric phenols, mainly 4propyl-4-propenyl-phenol [18].

Catalytic depolymerization of birch-wood organosolv lignin was studied in supercritical ethanol at $260{ }^{\circ} \mathrm{C}$ [19]. Different acid-basic materials, namely sepiolite, zeolite ZSM-5 supported on $\mathrm{Al}_{2} \mathrm{O}_{3}$ and Sibunit graphite-like mesoporous carbon, $\mathrm{Ru}$-containing catalysts based on these supports were used in lignin depolymerization process. The catalyst Ru/Sibunit allows to avoid coke formation, increases the amount of aromatic monomers and the total yield of liquid products up to $76 \%$.

The promising catalytic processes in wood biorefinery include, as a key stage, biomass fractionation on polysaccharides and lignin and their subsequent transformation to various chemicals and liquid biofuels.

The known ways of lignocelluloses biomass fractionation can be united into two groups. In one of them the cellulose and hemicelluloses are removed and the lignin remains as a rest, another includes methods in which the lignin is removed.

Reductive catalytic fractionation is an effective way to separate lignocellulosic biomass into lignin-based soluble mono-, di- and oligomers while retaining most of the carbohydrates in the pulp [20-22].

Single-stage processes of wood fractionation on cellulose and soluble lignin, based on the oxidative depolymerization of lignin in "hydrogen peroxide-acetic acid-water" medium at 120 $130{ }^{\circ} \mathrm{C}$ in the presence of different catalysts were suggested [23]. At optimum conditions of wood peroxide delignification in the presence of $\mathrm{H}_{2} \mathrm{SO}_{4}$ catalysts $(2 \mathrm{wt} \%)$ and $\mathrm{TiO}_{2}(0,5 \mathrm{wt} \%)$ the cellulosic products containing less than $1 \mathrm{wt} \%$ of residual lignin can be obtained with an acceptable yield (44-48 wt\% on abs. dry wood) along with soluble products from lignin and hemicelluloses.

It was shown that the use of small particles of wood, high liquid to wood ratio (LWR) and the intensive mixing of the reaction solution allows to reduce the external diffusion 
limitations and to provide a high rate of aspen wood peroxide delignification under mild conditions $\left(70-100{ }^{\circ} \mathrm{C}\right.$, atmospheric pressure) in the presence of $2 \% \mathrm{H}_{2} \mathrm{SO}_{4}$ catalyst [24].

In this paper the two ways of catalytic depolymerization of native and isolated wood lignins are described: the peroxide delignification of hardwood (aspen, birch) and softwood (abies) over the catalyst $\mathrm{TiO}_{2}$ in the medium of acetic acid - water at mild conditions $\left(\leq 100{ }^{\circ} \mathrm{C}\right.$, atmospheric pressure) and the thermal dissolution of organosolv lignins (ethanol-lignin and acetone-lignin) in supercritical alcohols (ethanol and butanol) over solid Ni-containing catalysts.

\section{Experimental}

\subsection{Catalyst preparation and characterization}

Preparation of $\mathrm{TiO}_{2}$

The synthesis of titanium dioxide was carried out by hydrolysis of ammonia solution of titanium tetrachloride with the subsequent calcination of a titanium (IV) hydroxide according to [25].

The necessary amount of $\mathrm{TiCl}_{4}$ was slowly added to a chemical glass with distilled water and the mixture was boiled within 10 minutes. Then a solution was cooled up to the temperature of $70-80{ }^{\circ} \mathrm{C}$ and $\mathrm{NH}_{4} \mathrm{OH}$ was added up to full sedimentation of $\mathrm{Ti}(\mathrm{OH})_{4}$. Precipitate was filtered on Buchner funnel and washed out by hot water from chlorine ions. Obtained paste of titanium hydroxide (IV) was then transfered to Petri's dish and dried up in muffler at $110^{\circ} \mathrm{C}$ up to the constant weight. The dried-up precipitate was placed to the porcelain boat and calcinated in the muffle furnace at various temperatures within one hour.

For obtaining $\mathrm{TiO}_{2}$ samples in the rutile modifications, the dried-up precipitate was calcinated at $800{ }^{\circ} \mathrm{C}$ within one hour, then crushed in an agate mortar, washed out by water from chlorine ions and calcinated at $1000{ }^{\circ} \mathrm{C}$ within 1,5 hours.

\section{Preparation of $\mathrm{NiCuMo} / \mathrm{SiO}_{2}$}

Catalysts $\mathrm{NiCuMo} / \mathrm{SiO}_{2}$ were obtained from nickel (II) carbonate basic hydrate $\mathrm{NiCO}_{3}$. $\mathrm{mNi}(\mathrm{OH})_{2} \mathrm{nH}_{2} \mathrm{O}$, copper(II) carbonate basic $\mathrm{CuCO}_{3} \cdot \mathrm{mCu}(\mathrm{OH})_{2}$, molybdenum(VI) oxide $\mathrm{MoO}_{3}$, and an alcohol solution of ethyl silicate-32 in the presence of ammonia water (25\%), using the sol-gel technique described in [26]. The resulting viscous paste was then dried at $100^{\circ} \mathrm{C}$ and calcined at $500^{\circ} \mathrm{C}$. The samples were heated to $500^{\circ} \mathrm{C}$ in the $\mathrm{H}_{2}$ (flow) in a quartz reactor, kept at this temperature for $1 \mathrm{~h}$, and then cooled and passivated with a mixture of $\mathrm{O}_{2}(2 \%) / \mathrm{N}_{2}$ [27]. 


\subsection{Initial wood materials}

Air dry sawdust (fraction 0.5-2.0 mm) of birch-wood, aspen-wood and abies-wood were used in experiments. The contents of cellulose, lignin and hemicelluloses in wood were defined by analytical methods, common in wood chemistry [28]. The cellulose content in wood was defined by Kurschner method. The lignin content was determined by hydrolysis of the sample with $72 \mathrm{wt} \%$ of sulfuric acid at $20{ }^{\circ} \mathrm{C}$ for $2.5 \mathrm{~h}$, followed by dilution of a solution with water and boiling for $4 \mathrm{~h}$. The hemicelluloses content was defined by McKein and Shoorly method using the hydrolysis by $2 \mathrm{wt} \% \mathrm{HCl}$ at $100{ }^{\circ} \mathrm{C}$ during $3 \mathrm{~h}$.

The composition of wood samples is given in Table 1 .

\section{Table 1}

Composition of wood samples.

\begin{tabular}{lllll}
\hline \multirow{2}{*}{ Wood } & \multicolumn{4}{c}{ Composition, wt \% } \\
\cline { 2 - 5 } & & Cellulose & Hemicelluloses & Lignin \\
\hline Aspen-wood & 46.3 & 24.5 & 21.9 & \\
Birch-wood & 46.5 & 27.2 & 21.8 & \\
Abies-wood & 45.7 & 17.7 & 25.3 & \\
\hline
\end{tabular}

Samples of acetone-lignin and ethanol-lignin were isolated from aspen-wood by methods described in $[29,30]$.

For isolation of acetone-lignin the treatments of aspen-wood sawdust (fraction less $0.5 \mathrm{~mm}$.) at first by water at $180^{\circ} \mathrm{C}$ during $1 \mathrm{~h}$ and then by boiling acetone (high purity, EKOS1, Russia) during $1 \mathrm{~h}$ were used. Yield of acetone-lignin was $29.5 \mathrm{wt} \%$ from content of Klason lignin in the wood.

Ethanol-lignin was isolated from aspen-wood (fraction less $0.5 \mathrm{~mm}$ ) by treatment of 60 wt\% ethanol-water mixture (high purity, EKOS-1, Russia) at $190{ }^{\circ} \mathrm{C}$ during $3 \mathrm{~h}$. Yield of ethanol-lignin was $56 \mathrm{wt} \%$ from content of Klason lignin in the wood.

The elemental composition of organosolv lignins was determined using Thermo quest HCNS - O EA FLASH TM 1112 analyzer.

The elemental composition of lignins is given in Table 2.

\section{Table 2}

Elemental composition of organosolv lignins.

\begin{tabular}{lcccc}
\hline Lignin & \multicolumn{4}{c}{ Elemental composition, wt\% } \\
\cline { 2 - 5 } & $\mathrm{C}$ & $\mathrm{H}$ & $\mathrm{O}$ & Ash \\
\hline Acetone-lignin & 64.6 & 6.8 & 26.7 & 0.5 \\
Ethanol-lignin & 67.2 & 6.7 & 25.1 & 0.4 \\
\hline
\end{tabular}




\subsection{Peroxide catalytic delignification of wood}

Catalytic delignification of wood sawdust by $\mathrm{H}_{2} \mathrm{O}_{2}$ was carried out as in [31] using 250 $\mathrm{cm}^{3}$ glass reactor equipped with mechanical stirrer, reflux condenser and thermometer. Wood sawdust (10 g) was placed into glass reactor. Then, a mixture of glacial acetic acid (high purity, Ekos-1, Russia), hydrogen peroxide (high purity, Ekos-1, Russia), distilled water and $\mathrm{TiO}_{2}$ was added. The reaction mixture was vigorously stirred $(700 \mathrm{rpm})$ at selected temperature (70-100 ${ }^{\circ} \mathrm{C}$ ) during 1-4 h. Composition of the of reaction mixture was varied in the following range: hydrogen peroxide 3-7 wt \%, acetic acid 15-40 wt\%, liquid/wood ratio (LWR) -10-15. Concentration of $\mathrm{TiO}_{2}$ catalyst was $1 \mathrm{wt} \%$. When the reaction was completed, the solid product was separated under vacuum using Buchner funnel, following by washing distilled water and drying at $105^{\circ} \mathrm{C}$ until constant weight.

Such parameter as the residual lignin content in cellulosic product was used to evaluate the delignification activity of $\mathrm{TiO}_{2}$ catalyst. The cellulosic product yield was estimated by gravimetric method and calculated as follows: $\mathrm{Y}=\left(\mathrm{m} / \mathrm{m}_{\mathrm{o}}\right) \times 100$, where $\mathrm{Y}-$ yield of cellulosic product, wt $\% ; \mathrm{m}$ - weight of abs. dry cellulosic product, $\mathrm{g} ; \mathrm{m}_{\mathrm{o}}-$ weight of abs. dry wood, $\mathrm{g}$.

\subsection{Conversion of organosolv lignin in supercritical alcohols}

The thermal conversion of organosolv lignins in supercritical alcohols was carried out at $250-350{ }^{\circ} \mathrm{C}$ in a rotating autoclave (Autoclave Engineers, USA) of $300 \mathrm{~cm}^{3}$ volume as in [32].

A mixture $3 \mathrm{~g}$ lignin and $0.3 \mathrm{~g}$ catalyst crushed to the particles with the average size less $0.5 \mathrm{~mm}$ and $15 \mathrm{ml}$ of ethanol or butanol (high purity, Ekos-1, Russia) was placed into autoclave. Air was removed from the sealed autoclave by purging it with argon through its stop valves. Thereafter, the autoclave was heated at a rate of $10 \mathrm{C} / \mathrm{min}$ to the desired temperature and was kept at this temperature for $1 \mathrm{~h}$ under vigorous mixing $(850 \mathrm{rpm})$. Under the used supercritical conditions, the pressure in the autoclave was 5.0 $\mathrm{MPa}$ for butanol (critical pressure and temperature 4.6 $\mathrm{MPa}$ and $288^{\circ} \mathrm{C}$ ) and $11.6 \mathrm{MPa}$ for ethanol (critical pressure and temperature 6.4 $\mathrm{MPa}$ and $243{ }^{\circ} \mathrm{C}$. Then the autoclave was cooled to room temperature and the products were quantitatively washed out of the autoclave. The condensed products were filtered through a filter paper (blue ribbon) in a vacuum using a Büchner funnel. The filtration residue was sequentially extracted with hexane, diethyl ether and acetone (all high purity, Ekos-1, Russia). The extract was dried to a constant weight under vacuum at room temperature. The yields of extracts and solid residues were determined by the gravimetric method after solvent removal. 


\subsection{Methods of analysis}

The content of cellulose, hemicelluloses and lignin in the cellulosic products was defined by chemical methods generally accepted in wood chemistry [28].

Infrared spectroscopy analysis (FTIR) was carried out in transmission mode. Samples of cellulose (4 mg for each) were prepared in tablets with matrix $\mathrm{KBr}$. The spectra were recorded with Bruker Tensor -27 in the range of wavelength $4000-400 \mathrm{~cm}^{-1}$. Spectral data were processed by the program OPUS/YR (version 2.2).

X-ray diffraction analysis was carried out on PANalytical X'Pert Pro diffractometer using $\mathrm{Cu}$-Ka source $(\mathrm{A}=0,154 \mathrm{~nm})$ in the $2 \theta$ range $5-70^{\circ}$ and scanning step width of $0,01 \%$ scan. The cellulose samples were analyzed by the powder method in cuvette with $2,5 \mathrm{~cm}$ diameter.

Crystallinity index (CI) was calculated from the ratio of the height between the intensity of the crystalline peak and total intensity after subtraction of the background signal [33]: $\mathrm{CI}=\left(\mathrm{I}_{002}-\right.$ $\left.I_{\mathrm{AM}}\right)$ / $\left(\mathrm{I}_{002}\right)$, where $\mathrm{I}_{002}$ - is the height of the 002 peak; $\mathrm{I}_{\mathrm{AM}}$ - is the height of the minimum between the 002 and the 101 peaks.

The liquid products of wood peroxide delignification and of lignin conversion in supercritical alcohols were analyzed by GC-MS using Agilent 7890A chromatograph fitted with an Agilent 7000A Triple Quad mass-selective detector (Agilent, United States) by recording the total ion current. The products were separated in an HP-5MS capillary column (30 m in length, $0.25 \mathrm{~mm}$ in inner diameter) in the temperature programmed mode while raising the temperature from 40 to $250^{\circ} \mathrm{C}$ at a rate of $3^{\circ} \mathrm{C} / \mathrm{min}$.

Molecular weight and molecular-weight distribution of organosolv lignins were examined using a gel permeation chromatograph (“Agilent Technologies@ 1260Infinity, U.S.) with a refractive index detector, using an Agilent PLgel Mixed-C column. Chloroform was used as the eluent, with a flow rate of $1.0 \mathrm{ml} / \mathrm{min}$ at $40{ }^{\circ} \mathrm{C}$. Typical sample volumes were $50 \mathrm{ml}$ at a polymer concentration of $2 \mathrm{mg} / \mathrm{ml}$. Narrow polydispersity polystyrene standards (Agilent, U.S.) were used to generate a universal calibration curve, from which molecular weights (weight average, $\mathrm{M}_{\mathrm{w}}$, and number average, $\mathrm{M}_{\mathrm{n}}$ ) and polydispersity were determined.

Thermal properties of lignin samples were studied using "Netzsch STA 449F1" instrument with a hearting rate of $10^{\circ} \mathrm{C} / \mathrm{min}$. For each experiment $\sim 5 \mathrm{mg}$ of lignin samples were employed. The samples were heated in the temperature range $30-800{ }^{\circ} \mathrm{C}$.

NMR data were collected on a Bruker Avance III 600 spectrometer system (14.1 T, Bruker, Germany) at $295 \mathrm{~K}$. Samples of 5-10 mg of lignin were placed into a $5 \mathrm{~mm}$ NMR tube and dissolved in $0.5 \mathrm{ml}$ of DMSO- $\mathrm{d}_{6}$. The two-dimensional multiplicity edited ${ }^{1} \mathrm{H}-{ }^{13} \mathrm{C}$ heteronuclear single quantum correlation (HSQC) spectra were recorded with four scans of 2048 
data points, 256 increments and relaxation delay of $2.5 \mathrm{~s}$. All spectra were acquired and processed using Top Spin 2 software supplied with the spectrometer.

The specific surface areas and pore volumes of the catalysts were measured using nitrogen adsorption at $77 \mathrm{~K}$ on a Micromeritics ASAP 2020 analyzer.

The electron images were obtained by scanning electron microscopy (SEM) TM-1000 HITACHI (Japan) with acceleration potentional $15 \mathrm{kV}$. Samples were coated on carbon support.

\section{Results and discussion}

\subsection{Peroxide delignification of hardwood and softwood over catalyst $\mathrm{TiO}_{2}$}

\subsubsection{Influence of a state of $\mathrm{TiO}_{2}$ on catalytic activity in aspen wood delignification}

In plant biomass the cellulose, hemicelluloses and lignin are tightly bond with one another. Preliminary fractionation of biomass on polysaccharides and lignin opens new prospects for the production of bio-based products. The features of hardwood and softwood peroxide catalytic fractionation in the acetic acid - water medium over $\mathrm{TiO}_{2}$ catalyst at mild conditions were compared in the present study.

Earlier [23] the activity of soluble and solid catalyst $\left(\mathrm{H}_{2} \mathrm{SO}_{4}, \mathrm{H}_{2} \mathrm{MoO}_{4}, \mathrm{Na}_{2} \mathrm{MO}_{4}, \mathrm{TiO}_{2}\right)$ in peroxide delignification of hardwood and softwood was studied at the elevated temperature (120 $-130{ }^{\circ} \mathrm{C}$ ) and pressure.

Recently it was shown that the decrease of wood particles sizes, the use of vigorous agitation of the reaction mixture and the high liquor to wood ratio (LWR) allow to reduce the diffusion limitations and to decrease the temperature of wood peroxide delignification up to 70 $100{ }^{\circ} \mathrm{C}[24,34]$.

Catalyst $2 \mathrm{wt} \% \mathrm{H}_{2} \mathrm{SO}_{4}$ has a high activity in peroxide delignification of aspen-wood at temperatures $90-100{ }^{\circ} \mathrm{C}$ [24]. But disadvantages of this catalyst are its high toxicity and corrosive activity. Therefore, it was suggested by us to use for the abies wood peroxide delignification under mild conditions $\left(\leq 100^{\circ} \mathrm{C}\right.$, atmospheric pressure $)$ the more technologically convenient $\mathrm{TiO}_{2}$ catalyst [34].

Catalytic activity of $\mathrm{TiO}_{2}$ in the peroxide delignification of wood is due to its ability to initiate the formation of radicals $\bullet \mathrm{OH}$ and $\bullet \mathrm{OOH}$ from $\mathrm{H}_{2} \mathrm{O}_{2}$ [35]. Being formed radicals participate in reactions of oxidative fragmentation of wood lignin [36].

It is known that catalytic properties of $\mathrm{TiO}_{2}$-based catalysts are sensitive to the method of their preparation [37].

Catalysts $\mathrm{TiO}_{2}$ prepared by titanium hydroxide treatment at $300{ }^{\circ} \mathrm{C}$ and $500{ }^{\circ} \mathrm{C}$ have a crystal modification of anatase. This conclusion is confirmed by data of X-ray diffraction analysis (Fig. 1) 

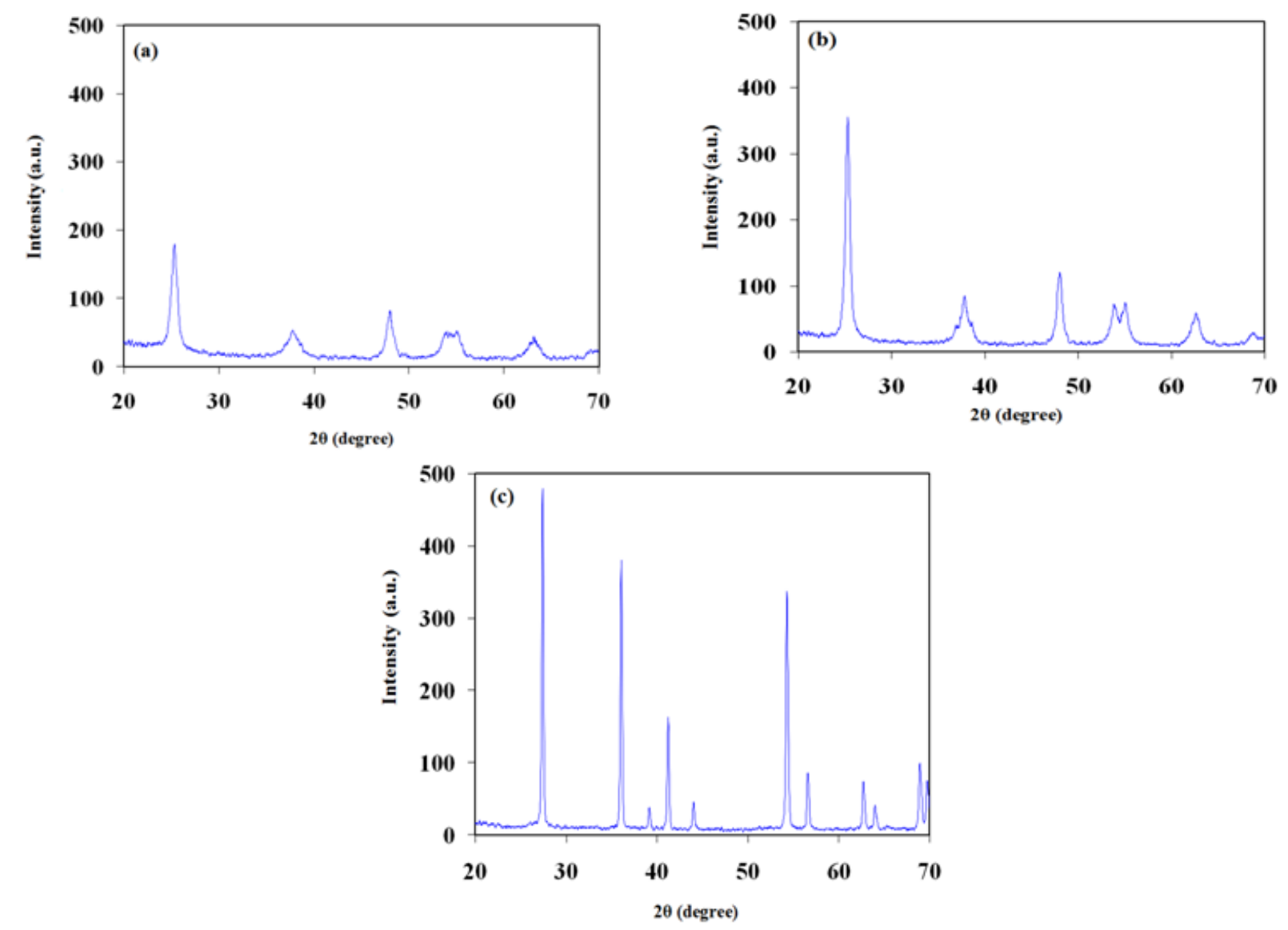

Fig. 1. X-ray diffraction pattern of $\mathrm{TiO}_{2}$ samples treated at temperatures $300^{\circ} \mathrm{C}(\mathrm{a}) ; 500{ }^{\circ} \mathrm{C} \mathrm{(b)}$; $1000{ }^{\circ} \mathrm{C}(\mathrm{c})$.

The increase of a temperature of $\mathrm{TiO}_{2}$ treatment to $1000{ }^{\circ} \mathrm{C}$ promotes the transformation of its anatase form into rutile form. The high temperature treatment also reduces the specific surface area of titanium dioxide and increases the size of pores (Table 3).

According to SEM data the crystals of $\mathrm{TiO}_{2}$ in a rutile modification have a spherical form (Fig. 2).

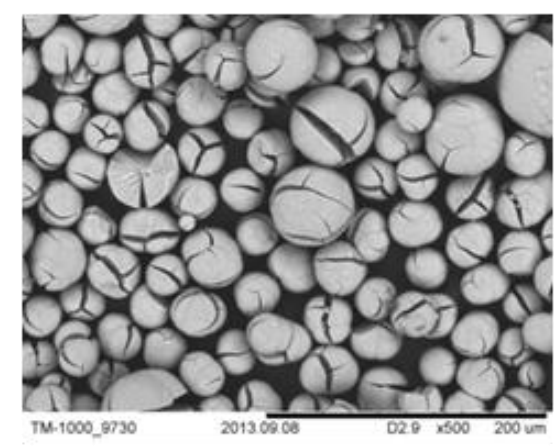

Fig. 2. SEM image of sample of titanium dioxide in rutile modification treated at $1000{ }^{\circ} \mathrm{C}$.

The sizes of $\mathrm{TiO}_{2}$ particles are varied between $10-50 \mu \mathrm{m}$.

IR-spectra of $\mathrm{TiO}_{2}$ samples of anatase and rutile modifications were compared (Fig. 3). The absorption bands corresponding to deformation (1040-1140 $\left.\mathrm{cm}^{-1}\right)$ and stretching (3200-3400 $\mathrm{cm}^{-1}$ ) vibrations of $\mathrm{Ti}-\mathrm{O}-\mathrm{H}$ bonds are more intensive in the spectrum of $\mathrm{TiO}_{2}$-anatase samples 
indicating on the higher content of $\mathrm{OH}$-groups as compared to $\mathrm{TiO}_{2}$-rutile. The increase of temperature of $\mathrm{TiO}_{2}$ treatment from 300 to $1000{ }^{\circ} \mathrm{C}$ considerably decreases the intensity of peaks of OH-groups (Fig.3).
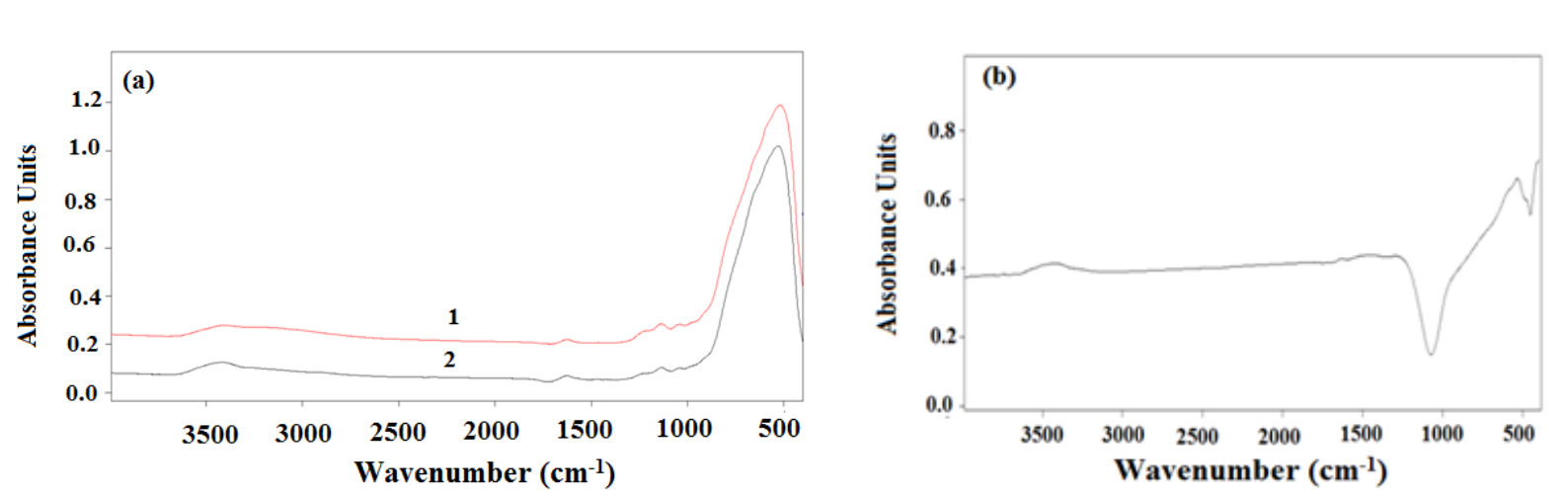

Fig. 3. IR spectra of samples of titanium dioxide in anatase modification (a), treated at $300{ }^{\circ} \mathrm{C}$ (1) and $500{ }^{\circ} \mathrm{C}(2)$ and in rutile modification (b) treated at $1000{ }^{\circ} \mathrm{C}$.

Catalytic properties of $\mathrm{TiO}_{2}$ samples in anatase and rutile modifications were compared in the process of aspen wood peroxide delignification at $100{ }^{\circ} \mathrm{C}$ (Table 3).

\section{Table 3}

Yield and composition of cellulosic products, obtained by aspen-wood peroxide delignification over $\mathrm{TiO}_{2}$ catalysts in anatase and rutile modification (reaction conditions: $100{ }^{\circ} \mathrm{C}, \mathrm{H}_{2} \mathrm{O}_{2} 5 \mathrm{wt} \%$, $\mathrm{CH}_{3} \mathrm{COOH} 25 \mathrm{wt} \%, \mathrm{TiO}_{2} 1 \mathrm{wt} \%$, LWR 15, time $4 \mathrm{~h}$ ).

\begin{tabular}{lccccccc}
\hline \multirow{2}{*}{$\begin{array}{c}\mathrm{TiO}_{2} \\
\text { modification }\end{array}$} & $\begin{array}{c}\text { Temperature } \\
\text { of } \mathrm{TiO}_{2} \\
\text { treatment, } \\
{ }^{\circ} \mathrm{C}\end{array}$ & $\begin{array}{c}\text { Surface } \\
\text { area } \\
\mathrm{m}^{2} / \mathrm{g}\end{array}$ & $\begin{array}{c}\text { Pore } \\
\text { size, } \\
\mathrm{nm}\end{array}$ & $\begin{array}{c}\text { Yield of } \\
\text { cellulosic } \\
\text { product, } \\
\text { wt\% } \%\end{array}$ & \multicolumn{2}{c}{$\begin{array}{c}\text { Composition of cellulosic product, } \\
\text { wt\%** }\end{array}$} \\
\hline Anatase & 300 & 111 & 12.4 & 68.3 & 77.4 & 9.8 & 12.3 \\
Anatase & 500 & 89 & 13.1 & 66.1 & 86.1 & 7.8 & 5.6 \\
Rutile & 1000 & 2 & 17.9 & 50.7 & 91.6 & 1.6 & 6.3 \\
\hline
\end{tabular}

on abs.dry wood, ${ }^{* *}$ on abs.dry cellulosic product

The obtained data show that at the same process conditions the use of titanium dioxide catalyst in rutile modification gives the cellulosic product with lower content of residual lignin and higher cellulose content, as compared to $\mathrm{TiO}_{2}$ in anatase modification.

Samples of $\mathrm{TiO}_{2}$ (anatase) which were obtained at temperatures $300{ }^{\circ} \mathrm{C}$ and $500{ }^{\circ} \mathrm{C}$ have a rather high surface area $\left(111 \mathrm{~m}^{2} / \mathrm{g}\right.$ and $\left.89 \mathrm{~m}^{2} / \mathrm{g}\right)$. Their lower catalytic activity in wood peroxide delignification can be explained by the following reasons. Probably, the smaller size of pores in anatase samples (12.4-13.1 nm) as compared to rutile sample $(17.9 \mathrm{~nm})$ reduces their catalytic activity in wood delignification owing to strengthening of diffusion limitations inside pores. The treatment of titanium dioxide at $1000{ }^{\circ} \mathrm{C}$, which promotes $\mathrm{TiO}_{2}$ transformation to rutile modification, reduces its surface area and increases the size of pores. The latter results in 
the reduction of diffusion limitation inside pore and increase the catalytic activity of $\mathrm{TiO}_{2}$ rutile in oxidative depolymerization of wood lignin.

Besides that, a higher concentration of hydrogen groups on the surface of anatase modification of $\mathrm{TiO}_{2}$, as compared to its rutile modification can prevent the formation from $\mathrm{H}_{2} \mathrm{O}_{2}$ the radical species $\left({ }^{\circ} \mathrm{OH}\right.$ and $\left.{ }^{\circ} \mathrm{OOH}\right)$ active in lignin oxidative depolymerization.

3.1.2. Kinetic studies and optimization of wood peroxide delignification over $\mathrm{TiO}_{2}$ catalyst

The kinetic regularities of peroxide fractionation of hardwood and softwood on cellulose and soluble products from hemicelluloses and lignin under mild conditions $\left(\leq 100{ }^{\circ} \mathrm{C}, 1 \mathrm{MPa}\right)$ over $\mathrm{TiO}_{2}$ catalyst were compared. Rutile modification of catalyst $\mathrm{TiO}_{2}$ was used in the experiments.

To optimize the processes of peroxide catalytic fractionation of different types of wood the influence of process conditions on the dynamics of lignin removal from wood was studied. It was found that the increase of temperature, concentrations of $\mathrm{H}_{2} \mathrm{O}_{2}$ and $\mathrm{CH}_{3} \mathrm{COOH}$ in the reaction mixture reduces the yield of cellulosic product and the contents of residual lignin and hemicelluloses in this product (Table 4, Fig. 4). At the same time the content of cellulose in cellulosic products is increased.

\section{Table 4}

Influence of temperature of wood peroxide delignification over $\mathrm{TiO}_{2}(1 \mathrm{wt} \%)$ catalyst on cellulosic products yield and composition.

\begin{tabular}{|c|c|c|c|c|}
\hline \multirow{2}{*}{ Temperature, ${ }^{\circ} \mathrm{C}$} & \multirow{2}{*}{$\begin{array}{l}\text { Yield of cellulosic } \\
\text { product, wt\%* }\end{array}$} & \multicolumn{3}{|c|}{ Composition of product, wt $\% * *$} \\
\hline & & cellulose & lignin & hemicelluloses \\
\hline \multicolumn{5}{|c|}{ Aspen-wood } \\
\hline 70 & 61.3 & 75.1 & 15.6 & 8.3 \\
\hline 80 & 54.5 & 84.3 & 6.3 & 8.0 \\
\hline 90 & 51,0 & 90.3 & 1.3 & 7.7 \\
\hline 100 & 50.2 & 91.1 & 0.6 & 7.4 \\
\hline \multicolumn{5}{|c|}{ Birch-wood } \\
\hline 70 & 59.0 & 78.8 & 12.7 & 8.3 \\
\hline 80 & 53,6 & 86.9 & 5.4 & 7.4 \\
\hline 90 & 50.2 & 92.8 & 1.1 & 5.8 \\
\hline 100 & 48.2 & 92.4 & 0.5 & 6.8 \\
\hline \multicolumn{5}{|c|}{ Abies-wood } \\
\hline 70 & 73.2 & 68.5 & 22.4 & 8.7 \\
\hline 80 & 66.5 & 75.4 & 17.0 & 7.2 \\
\hline 90 & 57.0 & 87.7 & 7.5 & 4.4 \\
\hline 100 & 52.6 & 94.1 & 1.8 & 3.8 \\
\hline
\end{tabular}



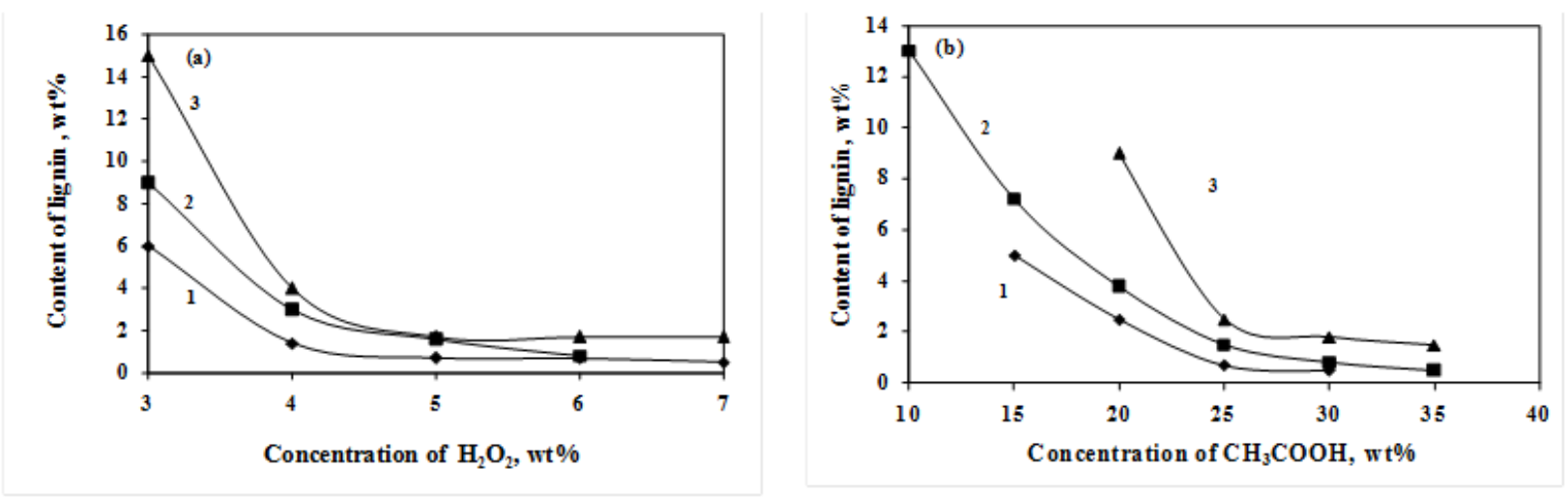

1 - aspen-wood, 2 - birch-wood, 3 - abies-wood

Fig. 4. Influence of concentration of $\mathrm{H}_{2} \mathrm{O}_{2}$ (a) and $\mathrm{CH}_{3} \mathrm{COOH}(\mathrm{b})$ on the content of residual lignin in cellulosic products obtained by peroxide delignification of different types of wood $\left(100^{\circ} \mathrm{C}, \mathrm{LWR}=15\right.$, time $\left.4 \mathrm{~h}, 1 \mathrm{wt} \% \mathrm{TiO}_{2}\right)$.

At the same delignification conditions the softwood lignin (abies-wood) depolymerizes more difficult than hardwood lignin (aspen and birch woods).

Numerical optimization of wood peroxide delignification over $\mathrm{TiO}_{2}$ catalyst was accomplished, according to the procedure described in [38]. As independed variables the following parameters were selected: $\mathrm{X}_{1}-\mathrm{H}_{2} \mathrm{O}_{2}$ concentration, $\% ; \mathrm{X}_{2}-$ liquid to wood ratio (LWR). Next fixed parameters: temperature $100^{\circ} \mathrm{C}$, time $4 \mathrm{~h}$, concentrations of $\mathrm{CH}_{3} \mathrm{COOH}-25$ $\mathrm{wt} \%, \mathrm{TiO}_{2}-1 \mathrm{wt} \%$ were used. Parameters for optimization: $\mathrm{Y}_{1}$ - yield of cellulosic product, $\mathrm{wt} \%, \mathrm{Y}_{2}-$ content of cellulose in product, $\mathrm{wt} \%, \mathrm{Y}_{3}-$ content of lignin in product, $\mathrm{wt} \%, \mathrm{Y}_{4}-$ content of hemicelluloses in product, wt $\%$.

Optimization was performed with the use of generalized parameter of optimization $\left(\mathrm{W}_{\mathrm{a}}\right)$, which was calculated using the following equation:

$$
W a=\frac{\sum_{j=1}^{p} \delta j d j}{\sum_{j=1}^{p} \delta j}
$$

Where $\delta$ - the weight of the output parameter $0 \leq \delta_{j} \leq 1 ; d_{j}$ - private utility function which was calculated using the following equation:

$$
\mathrm{dj}=\frac{\varphi_{\mathrm{o}}(\mathrm{x})-\mathrm{y}_{\mathrm{j}}^{(-)}}{\mathrm{y}_{\mathrm{j}}^{(+)}-\mathrm{y}_{\mathrm{j}}^{(-)}}
$$

Where $\varphi_{0}(x)$ - the response of output parameter at the point $\mathrm{X} ; y_{j}^{(+)}$and $y_{j}^{(-)}-$the best and worst values of the output parameters within the studied region.

Analysis of variances showed that the effect of both factors $X_{1}$ and $X_{2}$ on the generalized parameter of optimization is statistically significant (P-Value less than 0.05 and the confidence level is above $95 \%$ ).

As a result of mathematical processing the following regression equations were obtained: 
for aspen-wood: $\mathrm{W}_{\mathrm{a}}=-1.3379+0.5373 \mathrm{X}_{1}+0.1332 \mathrm{X}_{2}-0.0380 \mathrm{X}_{1}{ }^{2}-0.0137 \mathrm{X}_{1} \mathrm{X}_{2}-0.0026 \mathrm{X}_{2}{ }^{2}$ for birch-wood: $\mathrm{W}_{\mathrm{a}}=-0.5829+0,2915 \mathrm{X}_{1}+0.0783 \mathrm{X}_{2}-0.0165 \mathrm{X}_{1}^{2}-0.0088 \mathrm{X}_{1} \mathrm{X}_{2}-0.0008 \mathrm{X}_{2}^{2}$

for abies wood: $\mathrm{W}_{\mathrm{a}}=0.5990+0.115 \mathrm{X}_{1}+0.1748 \mathrm{X}_{2}-0.0593 \mathrm{X}_{1}^{2}+0.0035 \mathrm{X}_{1} \mathrm{X}_{2}-0,0468 \mathrm{X}_{2}^{2}$

Response surfaces of the generalized parameter of optimization of different types of wood are presented on Fig. 5.
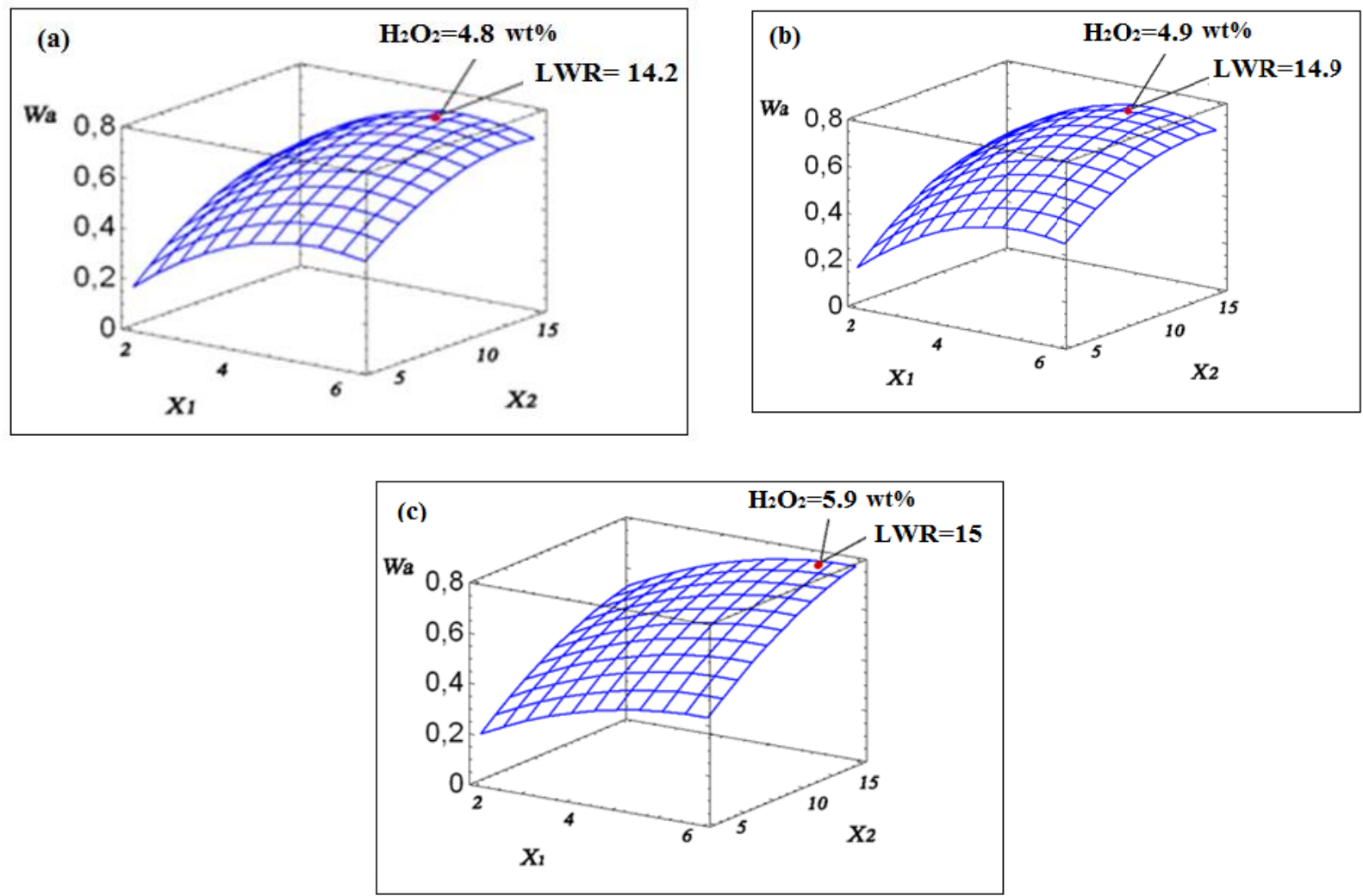

Fig. 5. The surfaces of generalized response of optimization parameters (Wa) of peroxide delignification of different types of wood over $\mathrm{TiO}_{2}$ catalyst. (a) aspen-wood; (b) birch-wood; (c) abies-wood.

Calculated output parameters at optimal conditions have the following values:

\section{Aspen-wood:}

$\mathrm{X}_{1}=4.8 \mathrm{wt} \% ; \mathrm{X}_{2}=14.2 ; \mathrm{Y}_{1}=52.2 \mathrm{wt} \% ; \mathrm{Y}_{2}=91.3 \mathrm{wt} \% ; \mathrm{Y}_{3}=0.9 \mathrm{wt} \% ; \mathrm{Y}_{4}=6.6 \mathrm{wt} \%$.

\section{Birch-wood:}

$\mathrm{X}_{1}=4.9 \mathrm{wt} \% ; \mathrm{X}_{2}=14.9 ; \mathrm{Y}_{1}=51.0 \mathrm{wt} \% ; \mathrm{Y}_{2}=92.7 \mathrm{wt} \% ; \mathrm{Y}_{3}=0.5 \mathrm{wt} \% ; \mathrm{Y}_{4}=6.5 \mathrm{wt} \%$.

\section{Abies-wood:}

$\mathrm{X}_{1}=5.9 \mathrm{wt} \% ; \mathrm{X}_{2}=15 ; \mathrm{Y}_{1}=54.9 \mathrm{wt} \% ; \mathrm{Y}_{2}=90.3 \mathrm{wt} \% ; \mathrm{Y}_{3}=3,0 \mathrm{wt} \% ; \mathrm{Y}_{4}=7.0 \mathrm{wt} \%$.

The calculated optimized conditions of wood peroxide delignification coincide well with obtained experimental data (Table 5). 


\section{Table 5}

Experimental data on optimized conditions of hardwood and softwood peroxide delignification at $100{ }^{\circ} \mathrm{C}$ over catalyst $\mathrm{TiO}_{2}(1 \mathrm{wt} \%)$.

\begin{tabular}{|c|c|c|c|c|c|}
\hline \multirow{2}{*}{$\begin{array}{l}\text { Wood } \\
\text { nature }\end{array}$} & \multirow{2}{*}{$\begin{array}{l}\text { Optimized } \\
\text { conditions }\end{array}$} & \multirow{2}{*}{$\begin{array}{l}\text { Yield of cellulosic } \\
\text { product, } \mathrm{wt} \% *\end{array}$} & \multicolumn{3}{|c|}{ Composition of product, $\mathrm{wt}^{\mathrm{*}} \%^{* *}$} \\
\hline & & & Lignin & Cellulose & Hemicelluloses \\
\hline $\begin{array}{l}\text { Aspen } \\
\text { wood }\end{array}$ & $\begin{array}{c}\mathrm{H}_{2} \mathrm{O}_{2}-5 \%, \\
\mathrm{CH}_{3} \mathrm{COOH}-25 \%, \\
\mathrm{LWR}-15\end{array}$ & 50.2 & 0.7 & 92.7 & 5.5 \\
\hline $\begin{array}{l}\text { Birch } \\
\text { wood }\end{array}$ & $\begin{array}{c}\mathrm{H}_{2} \mathrm{O}_{2}-5 \%, \\
\mathrm{CH}_{3} \mathrm{COOH}-25 \%, \\
\mathrm{LWR}-15\end{array}$ & 48.2 & 0.5 & 93.7 & 5.5 \\
\hline $\begin{array}{l}\text { Abies } \\
\text { wood }\end{array}$ & $\begin{array}{c}\mathrm{H}_{2} \mathrm{O}_{2}-6 \%, \\
\mathrm{CH}_{3} \mathrm{COOH}-30 \%, \\
\mathrm{LWR}-15\end{array}$ & 52.6 & 2.3 & 91.6 & 5.7 \\
\hline
\end{tabular}

The yields of cellulosic products obtained from different types of wood under optimized conditions are varied between 48.2-52.6 wt\% (Table 5). Initial softwood contains more lignin, then hardwood, therefore the higher concentration of hydrogen peroxide $(6 \mathrm{wt} \%)$ is needed for abies-wood delignification, as compared to aspen-wood and birch-wood.

\subsubsection{Composition and structure of products of wood peroxide catalytic delignification}

The structure of solid cellulosic products obtained by peroxide delignification of hardwood and softwood over $\mathrm{TiO}_{2}$ (rutile) catalyst at optimized process conditions (Table 5) was studied by FTIR and XRD methods.

The FTIR spectra of cellulosic products from wood and the commercial sample of MCC Vivapur are very similar (Fig. 6). All samples have an absorption bands attributed to microcrystalline cellulose $[39,40]$. The absence in the spectrum of cellulosic product from wood the peaks in the range $1509-1609 \mathrm{~cm}^{-1}$, which would correspond to $\mathrm{C}=\mathrm{C}$ aromatic skeletal vibrations, indicates the absence of residual lignin in the cellulosic product.

The absorption peak at $1430 \mathrm{~cm}^{-1}$ corresponds to the $\mathrm{CH}_{2}$ bending vibration that is attributed to the "crystallinity band" in the cellulose [41]. The band at $893 \mathrm{~cm}^{-1}$ was attributed to the $\mathrm{C}-\mathrm{O}-\mathrm{C}$ stretching vibration of $\beta-(1 \rightarrow 4)$-glycosidic linkages of cellulose, which was considered as an "amorphous band"' in the cellulose [41]. 


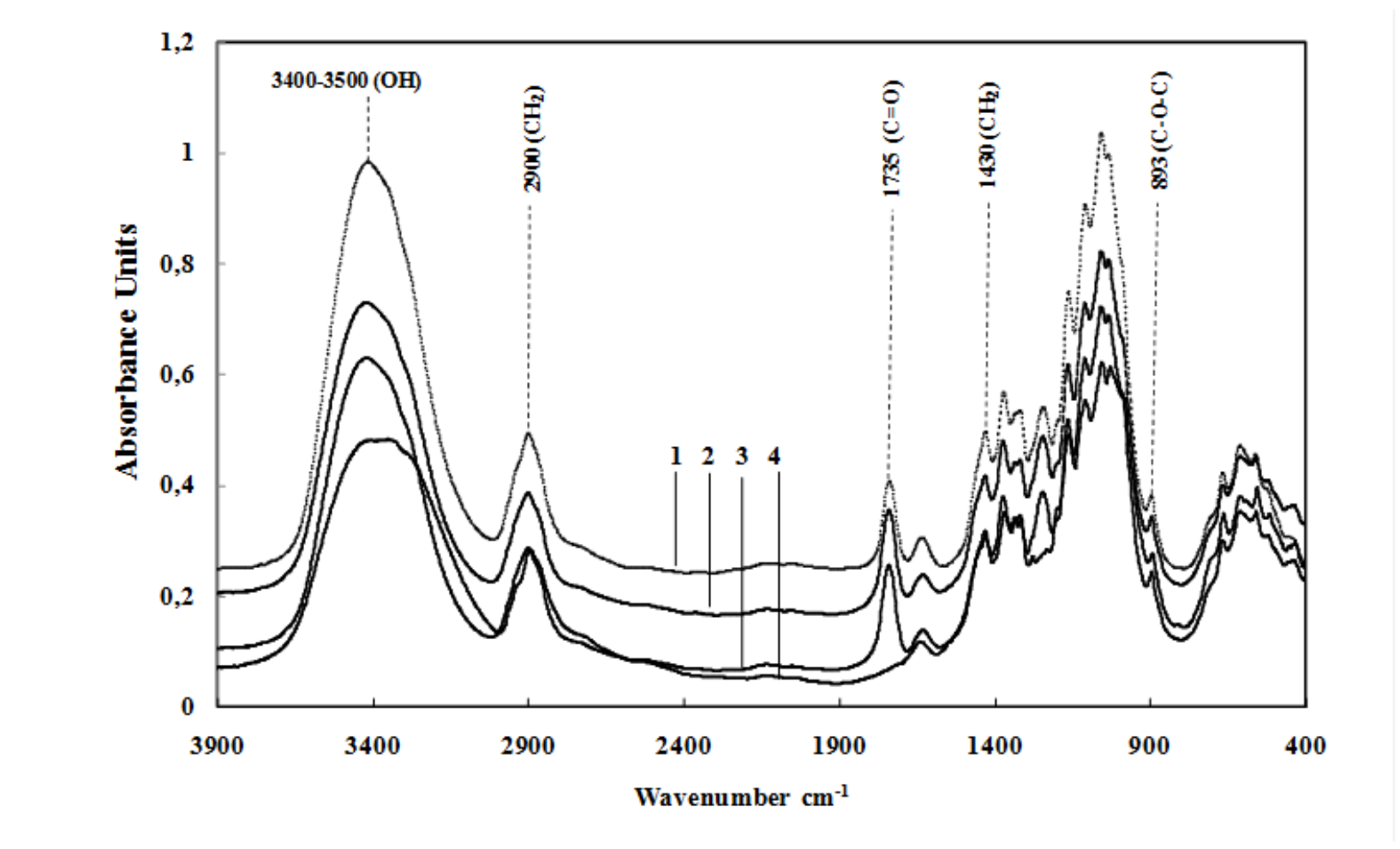

Fig. 6. Infrared spectra of cellulosic products obtained by peroxide delignification of different types of wood ( 1 - aspen; 2 - birch; 3 - abies) and of commercial microcrystalline cellulose Vivapur (4).

The absorption band, which corresponds to either the acetyl or uronic ester groups of hemicelluloses, normally appears in the region 1700-1740 $\mathrm{cm}^{-1}$ [42]. The presence of this band in the spectrum of cellulosic product from wood indicates that some part of hemicelluloses was not removed during wood delignification under the used conditions.

According to X-ray diffraction data (Fig. 7) the samples of cellulose obtained by peroxide delignification of aspen, birch and abies wood have the structure, similar to the commercial MCC. Difractograms of all cellulosic samples contain two intensive peaks with maximum $2 \theta$ equal $22.6^{\circ}$ (plane 002) and $16.2^{\circ}$ (plane 110). A well crystallized and homogeneous on the lattice parameters of MCC gives narrow and high diffraction peaks. X-ray data (Fig.7) suggests that the crystal structure of MCC samples obtained from wood is the monoclinic cellulose I [43].

According to the X-ray data, the crystallinity of MCC samples obtained from wood (6774\%) are close to the crystallinity of industrial MCC Vivapur and MCC Avicel PH 102 [44]. 


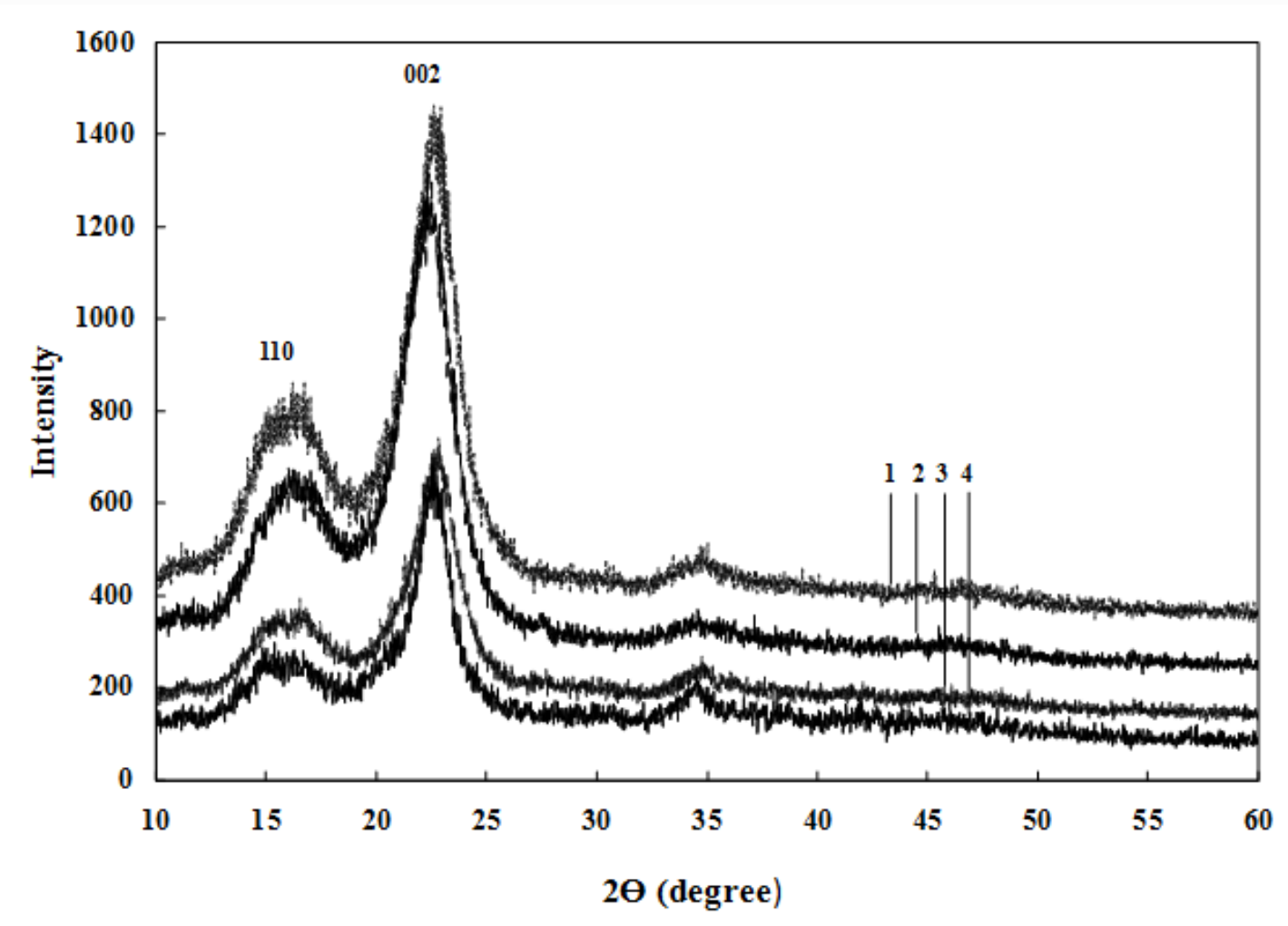

Fig. 7. Difractograms of cellulosic products obtained by peroxide delignification of different types of wood (1 - aspen; 2-birch; 3 - abies) and of commercial microcrystalline cellulose Vivapur (4).

It is known, that hydrogen peroxide is also an effective oxidant for aromatic ring cleavage reactions and the complete oxidation of lignin by $\mathrm{H}_{2} \mathrm{O}_{2}$ leads to the formation of organic acids as end products [45]. The o-quinone structures are likely oxidized to muconic acids, while pquinone structures may yield four-carbon acids (maleic acid, fumaric acid, malic acid, etc.) [5]. The transition- metal catalysts can accelerate the formation of reactive free-radical species from hydrogen peroxide which break the aromatic ring of lignin with the formation of organic acids.

The composition of soluble products obtained in the process of aspen wood peroxide delignification over catalyst $\mathrm{TiO}_{2}$ (rutile) at $100^{\circ} \mathrm{C}$ was studied using GC-MS method (Table 6). 


\section{Table 6}

Results of GC-MS study the composition of benzene-soluble products obtained by peroxide delignification of aspen wood over catalyst $\mathrm{TiO}_{2}$ (rutile) (reaction conditions: $100{ }^{\circ} \mathrm{C}$, $\mathrm{H}_{2} \mathrm{O}_{2} 5 \mathrm{wt} \%, \mathrm{CH}_{3} \mathrm{COOH} 25 \mathrm{wt} \%, \mathrm{TiO}_{2} 1 \mathrm{wt} \%$, LWR 15, time $4 \mathrm{~h}$ ).

\begin{tabular}{clc}
\hline Retention time, min & \multicolumn{1}{c}{ Compound } & Content, \%* \\
\hline 9.29 & Fumaric acid & 3.18 \\
12.44 & Levulinic acid & 1.43 \\
16.48 & Oxypropanoic acid & 0.83 \\
19.01 & Y -hydroxybutanoic acid & 0.77 \\
21.38 & Malic acid & 3.16 \\
24.45 & Adipic acid & 0.72 \\
25.84 & 3,4-Hydroxyfuranone & 0.02 \\
28.24 & p-hydroxybenzoic acid & 6.24 \\
29.97 & 2,3,4,5-tetrahydropentanoic acid 1.4 lactone & 5.66 \\
32.26 & D-glucose & 33.91 \\
38.54 & D-ribose & 3.54 \\
41.61 & Glucofuranoside & 6.91 \\
46.95 & Xylose & 29.80 \\
53.30 & Azelaic acid & 3.83 \\
\hline
\end{tabular}

*from the sum of areas of all peaks

Obtained results show, that the benzene-soluble products of wood peroxide catalytic delignification over catalyst $\mathrm{TiO}_{2}$ at $100^{\circ} \mathrm{C}$ mainly consist of monosaccharides and organic acids.

Aromatic compounds are present only in a low amounts which indicates oxidative degradation of aromatic units of lignin under the used conditions of wood catalytic delignification. The oxidation of benzene rings yields the fumaric, malic, oxypropanoic, $\Upsilon-$ hydroxybutanoic acids and of a small amount (6.24 \% rel.) of p-hydroxybenzoic acid (Table 6). The reactions of hydrolysis of hemicelluloses and amorphous cellulose give a significant amount of D-glucose (33.91\% rel.) and xylose (29.80\% rel.).

Thus, the results of the accomplished study demonstrate the possibility of efficient peroxide fractionation of hardwood and softwood at $100{ }^{\circ} \mathrm{C}$ over $\mathrm{TiO}_{2}$ (rutile) catalyst into microcrystalline cellulose and low molecular mass products mainly presented by organic acids and $\mathrm{C}_{6}$ and $\mathrm{C}_{5}-$ monosaccharides.

\subsection{Organosolv lignins depolymerization in supercritical alcohols}

\subsubsection{Characterization of the organosolv lignins}

Organosolv lignins have the hydrophobic properties. They are not soluble in water, but have a good solubility in many organic solvents [46]. The organosolv lignins do not contain sulfur and have lower molecular mass as compared to conventional technical lignins. Therefore they are convenient objects for the use in the processes of catalytic depolymerization into liquid phenolic and aromatic hydrocarbons. 
In this study acetone-lignin and ethanol-lignin isolated from aspen wood were characterized by FTIR, 2D NMR spectroscopy, gel permeation chromatography, elemental and thermogravimetric analysis.

IR spectra of acetone-lignin and ethanol-lignin contains adsorption bands characteristic for phenolic structural units of guaiacyl and syringyl types as well as aliphatic fragments and carboxylic groups (Fig. 8).

The broad intensive band at $3430 \mathrm{~cm}^{-1}$ belongs to the stretching vibrations of associated phenolic and aromatic hydroxyls. The intensive bands at $2935 \mathrm{~cm}^{-1}, 2851 \mathrm{~cm}^{-1}$ (C-H stretching vibrations in methyl and methylene groups) and at $1463 \mathrm{~cm}^{-1}$ (asymmetric deformation vibrations of these groups) indicates the presence of aliphatic fragments in lignins.

The groups of bands in the regions $1605-1593 \mathrm{~cm}^{-1}, 1515-1505 \mathrm{~cm}^{-1}, 1430-1422 \mathrm{~cm}^{-1}$ belong to the skeletal vibrations of aromatic ring. The bands at $1271-1266 \mathrm{~cm}^{-1}-$ skeletal vibrations of guaiacyl ring and stretching asymmetric vibrations of $\mathrm{C}_{\mathrm{ar}}-\mathrm{O}-\mathrm{C}$. The bands at $1230-1216 \mathrm{~cm}^{-1}$ - skeletal vibrations of syringyl ring and $\mathrm{C}-\mathrm{O}$ stretching vibrations in phenols $[47,48]$.

The comparison of the intensity of bands at $1271 \mathrm{~cm}^{-1}$ and $1216 \mathrm{~cm}^{-1}$ suggests that organosolv lignins from aspen wood contain more syringyl units, than guaiacyl units.
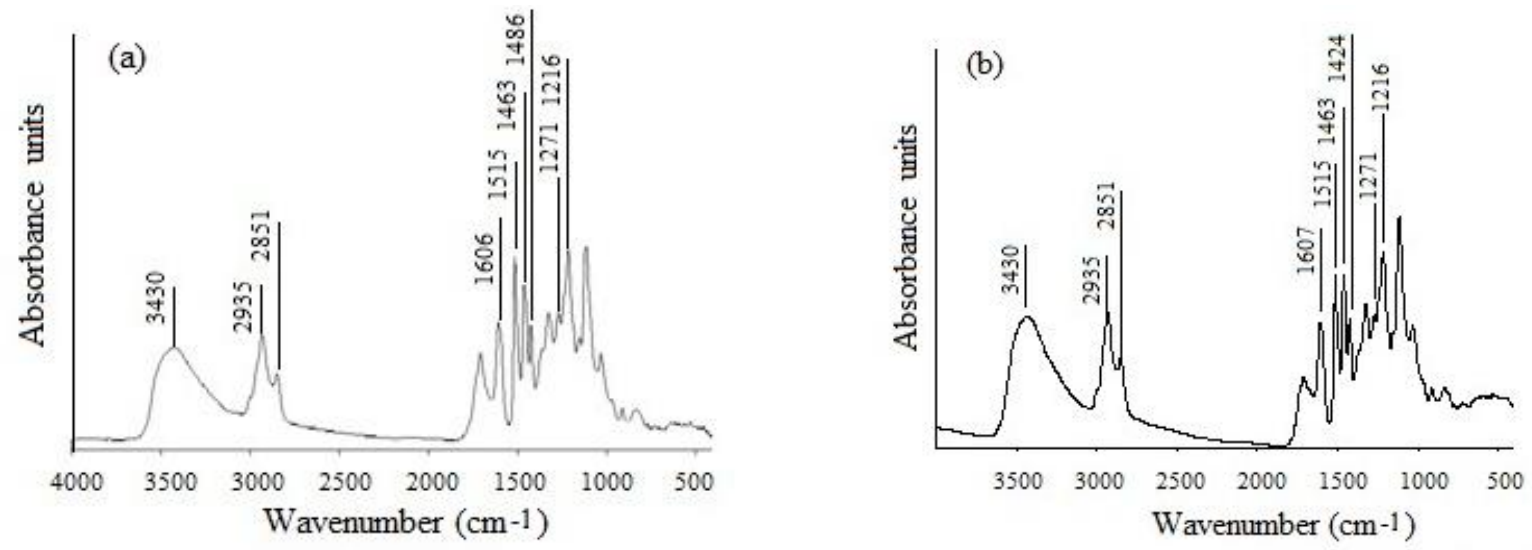

Fig. 8. FTIR spectra of acetone-lignin (a) and ethanol-lignin (b) obtained from aspen wood.

According to thermogravimetric data, the thermal decomposition of acetone-lignin and ethanol-lignin mainly proceeds in one stage. This is indicated by the appearance on the differential curve of the mass loss the peak of high intensity at $378{ }^{\circ} \mathrm{C}$ for ethanol-lignin and 368 ${ }^{\circ} \mathrm{C}$ for acetone-lignin (Fig. 9) 

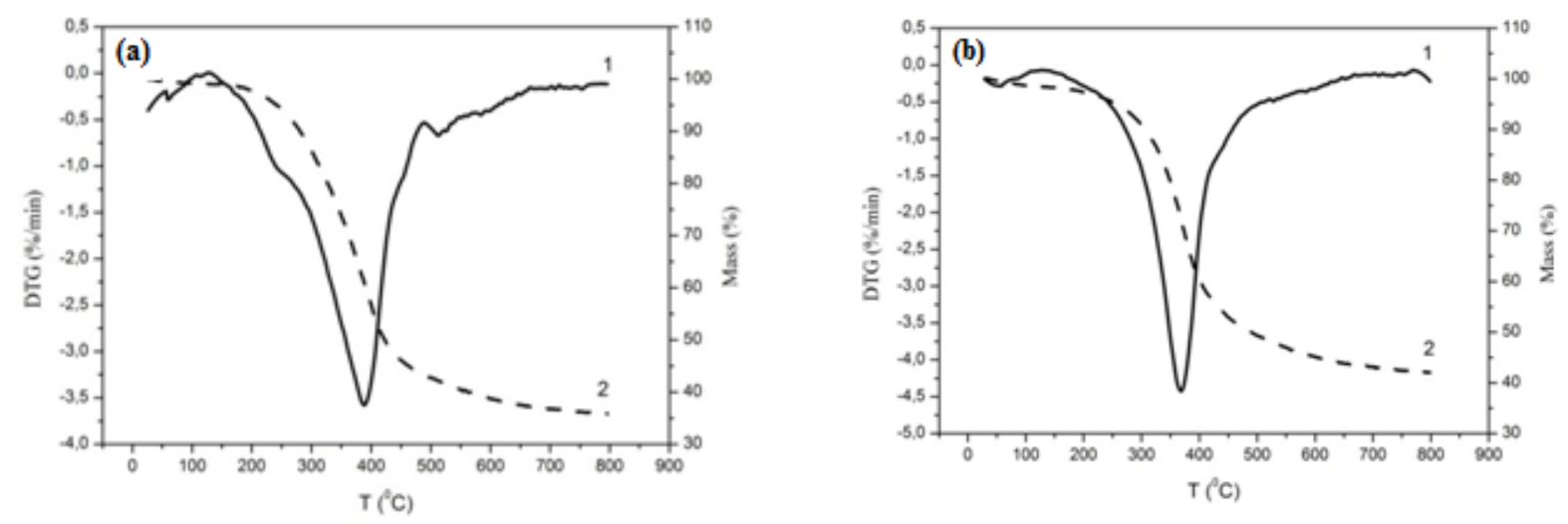

Fig. 9.Thermogravimetric DTG (1) and TGA (2) curves of ethanol-lignin (a) and acetone-lignin (b).

According to GPC data the samples of chloroform extracts of organosolv lignins are characterized by a wide distribution of molecular masses in the range 100-10000 Da. The peak on chromatograms with molecular weight less than 100 Da probably belongs to a low-molecular mass impurity. In general, the nature of the molecular weight distribution is similar for the samples of acetone-lignin and ethanol-lignin. Three peaks with $\mathrm{MM} \sim 250, \sim 600, \sim 900$ with significant overlap can be singled out in chromatograms of ethanol-lignin sample (Fig. 10 a).
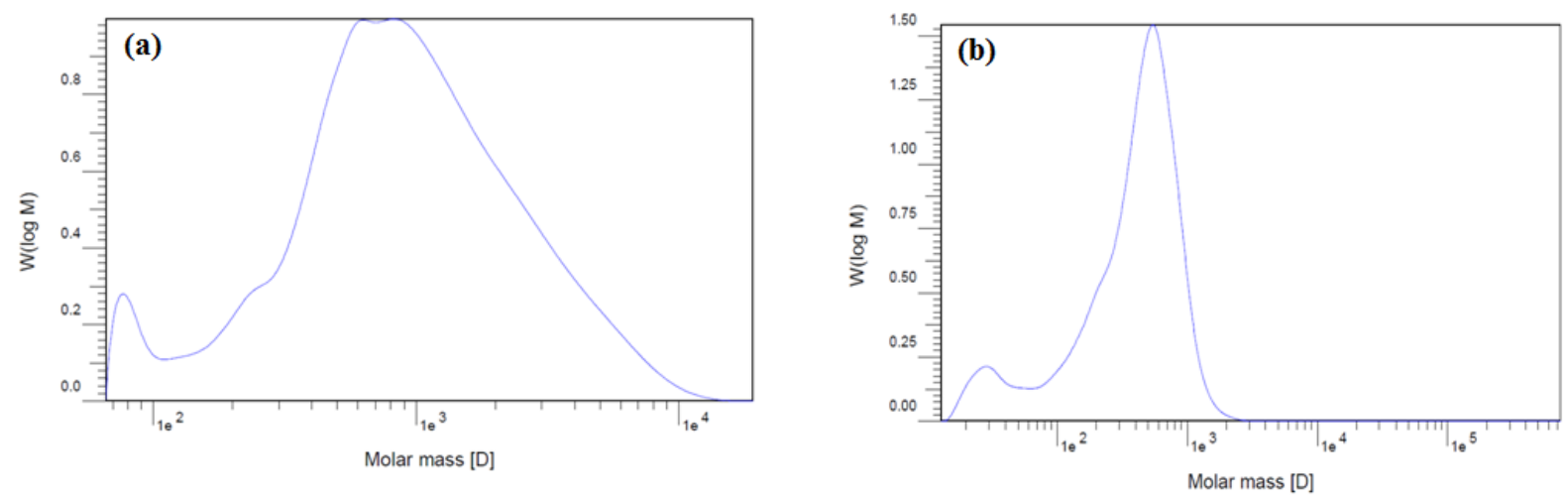

Fig. 10. Molecular weight distributions of chloroform extracts of ethanol-lignin (a) and acetonelignin (b).

It should be noted that the solubility of acetone-lignin in chloroform is lower than ethanol-lignin. Due to the low solubility, the maximum molecular weight of acetone-lignin does not exceed $2 \mathrm{kDa}$, and it characterizes by a single peak $(\sim 700 \mathrm{Da})$ with a low polydispersity index ( 1.5) (Fig. 10 b).

Lignin contours in the HSQC spectra (Fig. 11) were assigned with the use of the literature data [49-52].Typically, three main regions in HSQC spectra of lignocellulosic samples are observed: the aromatic region of lignin $(\delta \mathrm{C} / \delta \mathrm{H} 160-102 / 8.0-6.0)$, the aliphatic region of lignin (main inter units ranged from $\delta \mathrm{C} / \delta \mathrm{H} 90-50 / 6.0-3.0$ ), and the polysaccharide anomeric region $(\delta \mathrm{C} / \delta \mathrm{H} 110-60 / 6.0-3.0)$. In aspen organosolv lignins, the main linkages, such as $\beta-\mathrm{O}-4$ aryl ethers, resinols, phenylcoumarans could be assigned (Fig. 11). 

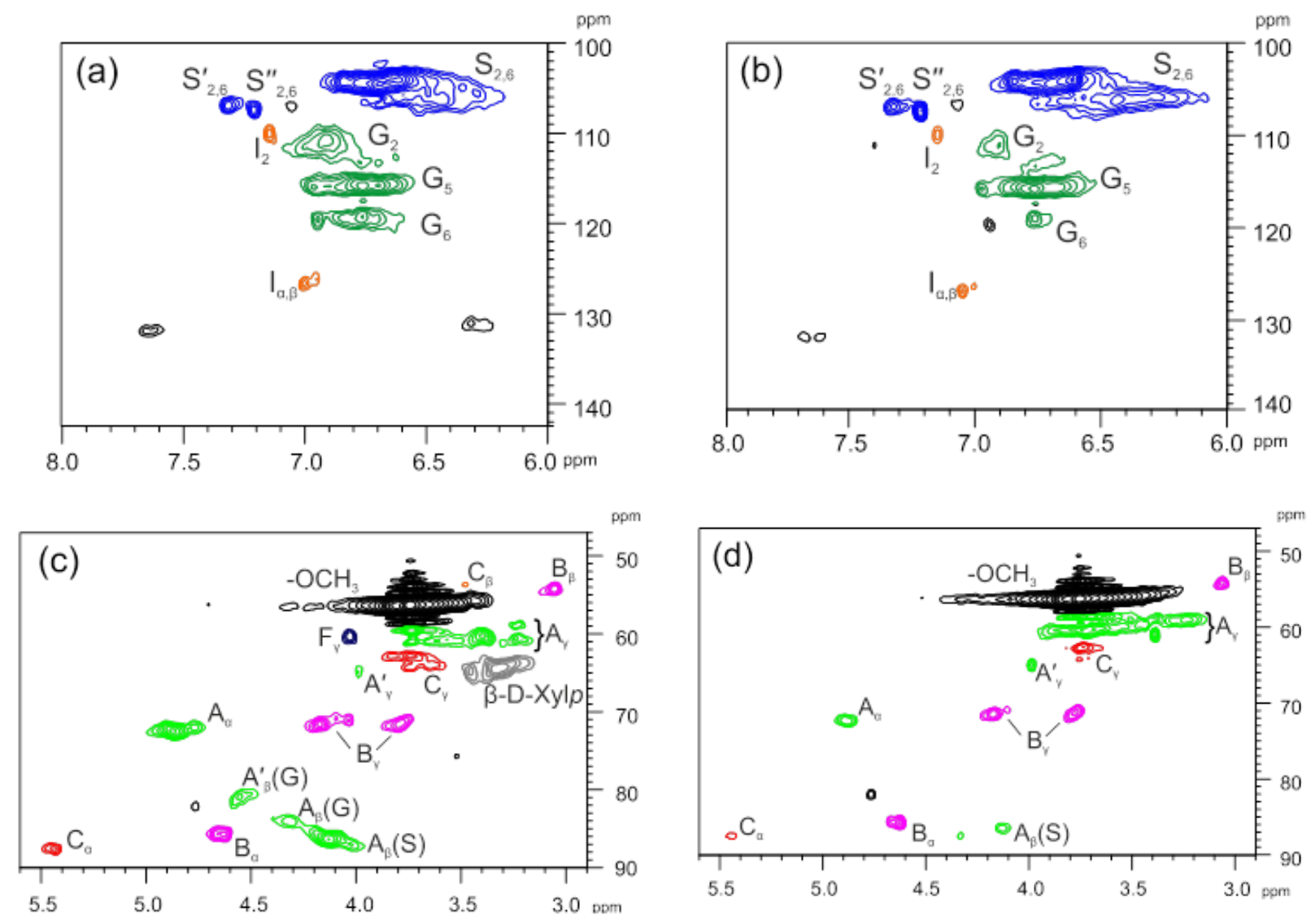

Fig. 11. ${ }^{1} \mathrm{H}-{ }^{13} \mathrm{C}$ HSQC NMR spectra of aspen lignin samples: ethanol-lignin aromatic (a) and aliphatic (c) region; aceton-lignin aromatic (b) and aliphatic (d) region.

The assignment of main lignin ${ }^{13} \mathrm{C}-{ }^{1} \mathrm{H}$ cross-signals in the HSQC spectra of aspen organosolv lignins is given in Table 7.

The comparison of ${ }^{1} \mathrm{H}-{ }^{13} \mathrm{C}$ HSQC NMR spectra of the aspen organosolv lignin showed that in both lignins there are correlation peaks at $\delta \mathrm{C} / \delta \mathrm{H} 72.5 / 4.87 \mathrm{ppm}\left(\mathrm{A}_{\alpha}\right)$ and $\delta \mathrm{C} / \delta \mathrm{H}$ 60.3-60.9/3.4-3.72 ppm $\left(\mathrm{A}_{\gamma}\right)$ assigned to $\beta-O-4$ aryl ether substructures. However, in acetonelignin, in contrast to ethanol-lignin, the single correlation peak at $\delta \mathrm{C} / \delta \mathrm{H} 86.2 / 4.13 \mathrm{ppm}$ is present. This peak assigned to the $\mathrm{CH}_{2}$-group in the $\beta$-position in syringyl substructures $\left(\mathrm{A}_{\beta}(\mathrm{S})\right)$.

For ethanol-lignin the peaks at $\delta \mathrm{C} / \delta \mathrm{H} 84.0 / 4.32 \mathrm{ppm}$ are also observed. These peaks assigned to the $\mathrm{CH}_{2}$ groups in the $\beta$-position of syringyl and guaiacyl units.

In the 2D-HSQC NMR spectra of ethanol-lignin the peak at $\delta \mathrm{C} / \delta \mathrm{H} 64.3 / 3.33 \mathrm{ppm}$, which was assigned to the $\mathrm{C}_{5}$ of $\beta$-D-xylopyranoside fragments of the lignin-carbohydrate complex, was also detected. This peak is absent in the spectra of acetone-lignin. 


\section{Table 7}

Assignment of main lignin ${ }^{13} \mathrm{C}-{ }^{1} \mathrm{H}$ cross-signals in the HSQC spectra of the aspen organosolv lignins.

\begin{tabular}{|c|c|c|}
\hline Label & $\delta \mathrm{C} / \delta \mathrm{H}(\mathrm{ppm})$ & Assignment \\
\hline $\mathrm{C}_{\beta}$ & $54.4 / 3.46$ & $\mathrm{C}_{\beta}-\mathrm{H}_{\beta}$ in phenylcoumarane substructures $(\mathrm{C})$ \\
\hline $\mathrm{B}_{\beta}$ & $54.3 / 3.06$ & $\mathrm{C}_{\beta}-\mathrm{H}_{\beta}$ in resinol substructures (B) \\
\hline$-\mathrm{OCH}_{3}$ & $56.2 / 3.76$ & $\mathrm{C}-\mathrm{H}$ in methoxyls \\
\hline $\mathrm{A}_{\gamma}$ & $60.3-60.9 / 3.4-3.72$ & $\mathrm{C}_{\gamma}-\mathrm{H}_{\gamma}$ in $\beta-O-4$ substructures (A) \\
\hline $\mathrm{F}_{\gamma}$ & $61.9 / 4.09$ & $\mathrm{C}_{\gamma}-\mathrm{H}_{\gamma}$ in cinnamyl alcohol end-groups $(\mathrm{F})$ \\
\hline $\mathrm{C}_{\gamma}$ & $62.8 / 3.74$ & $\mathrm{C}_{\gamma}-\mathrm{H}_{\gamma}$ in phenylcoumaran substructures $(\mathrm{C})$ \\
\hline$\beta$-D- & $64.3 / 3.33$ & $\beta$-D-Xylopyranoside \\
\hline \multicolumn{3}{|l|}{$\mathrm{Xyl} p$} \\
\hline $\mathrm{A}_{\gamma}^{\prime}$ & $64.7 / 3.99$ & $\mathrm{C}_{\gamma}-\mathrm{H}_{\gamma}$ in $\gamma$-acetylated $\beta-O-4^{\prime}$ substructures $\left(\mathrm{A}^{\prime}\right)$ and others \\
\hline $\mathrm{B}_{\gamma}$ & 71.6/3.89and 4.18 & $\mathrm{C}_{\gamma}-\mathrm{H}_{\gamma}$ in resinol substructures (B) \\
\hline $\mathrm{A}_{\alpha}$ & $72.5 / 4.87$ & $\mathrm{C}_{\alpha}-\mathrm{H}_{\alpha}$ in $\beta-O-4$ substructures (A) \\
\hline$A_{\beta}(G)$ & $84.0 / 4.32$ & $\mathrm{C}_{\beta}-\mathrm{H}_{\beta}$ in $\beta-O-4$ substructures linked to $\mathrm{G}$ units (A) \\
\hline $\mathrm{A}_{\beta}^{\prime}(\mathrm{G})$ & $80.7 / 4.55$ & $\mathrm{C}_{\beta}-\mathrm{H}_{\beta}$ in $\mathrm{C}_{\alpha}$-ethoxylation $\beta-O-4$ linkages \\
\hline $\mathrm{B}_{\alpha}$ & $85.5 / 4.64$ & $\mathrm{C}_{\alpha}-\mathrm{H}_{\alpha} \mathrm{in}$ resinol substructures (B) \\
\hline$A_{\beta}(S)$ & $86.2 / 4.13$ & $\mathrm{C}_{\beta}-\mathrm{H}_{\beta}$ in $\beta-O-4^{\prime}$ substructures linked to $\mathrm{S}$ units (A) \\
\hline $\mathrm{C}_{\alpha}$ & $87.5 / 5.44$ & $\mathrm{C}_{\alpha}-\mathrm{H}_{\alpha}$ in phenylcoumaran substructures (C) \\
\hline$S_{2,6}$ & $104.3 / 6.66$ & $\mathrm{C}_{2,6}-\mathrm{H}_{2,6}$ in etherified syringyl units $(\mathrm{S})$ \\
\hline $\mathrm{S}_{2,6}^{\prime}$ & $106.7 / 7.31$ & $\mathrm{C}_{2,6}-\mathrm{H}_{2,6}$ in oxidized $\left(\mathrm{C}_{\alpha}=\mathrm{O}\right)$ syringyl units $\left(\mathrm{S}^{\prime}\right)$ \\
\hline $\mathrm{S}_{2,6}^{\prime \prime}$ & 107.0/7.21 & $\mathrm{C}_{2,6}-\mathrm{H}_{2,6}$ in oxidized $\left(\mathrm{C}_{\alpha}=\mathrm{O}\right)$ syringyl units $\left(\mathrm{S}^{\prime \prime}\right)$ \\
\hline $\mathrm{I}_{2}$ & $110.0 / 7.15$ & $\mathrm{C}_{2}-\mathrm{H}_{2}$ in stilbenes units $(\mathrm{I})$ \\
\hline $\mathrm{G}_{2}$ & $111.0 / 6.90$ & $\mathrm{C}_{2}-\mathrm{H}_{2}$ in guaiacyl units $(\mathrm{G})$ \\
\hline $\mathrm{G}_{5}$ & $115.6 / 6.76$ & $\mathrm{C}_{2}-\mathrm{H}_{2}$ in guaiacyl units $(\mathrm{G})$ \\
\hline $\mathrm{G}_{6}$ & $119.2 / 6.76$ & $\mathrm{C}_{6}-\mathrm{H}_{6}$ in guaiacyl units $(\mathrm{G})$ \\
\hline $\mathrm{I}_{\alpha, \beta}$ & $126.0 / 7.00$ & $\mathrm{C}_{\alpha, \beta}-\mathrm{H}_{\alpha, \beta}$ in stilbenes units $(\mathrm{I})$ \\
\hline
\end{tabular}

\subsubsection{Organosolv lignin conversion in supercritical alcohols}

The effective depolymerization of lignin proceeds in supercritical lower alcohols (often ethanol and butanol) $[4,6,7]$. The choice of these alcohols is due to the fact that the values of their critical temperatures $\left(243{ }^{\circ} \mathrm{C}\right.$ for ethanol and $288{ }^{\circ} \mathrm{C}$ for butanol) are close to the temperature region of intensive thermal degradation of lignins. Besides, lignin is a waste of ethanol and butanol obtaining from wood and that allows its one-site valorization without the use of additional reagents and transport costs. Alcohols not only extract the products of thermal 
fragmentation of lignin but also they are able to alkylate them, preventing the secondary reactions of their condensation $[7,32]$.

The catalytic properties of Ni-containing catalysts were studied in conversions of ethanollignin in supercritical ethanol and butanol. Table 8 shows the composition of the catalyst samples.

Table 8

Characteristics of the studied Ni-containing catalysts.

\begin{tabular}{clcc}
\hline \multicolumn{1}{c}{ Catalyst } & Catalyst composition, wt $\%$ & $\begin{array}{c}\text { Specific } \\
\text { surface area } \\
\mathrm{m}^{2} / \mathrm{g}\end{array}$ & $\begin{array}{c}\text { Pore volume, } \\
\mathrm{cm}^{3} / \mathrm{g}\end{array}$ \\
\hline $\mathrm{NiCu} / \mathrm{SiO}_{2}(400)$ & $\mathrm{Ni}-56 ; \mathrm{Cu}-8.2 ; \mathrm{Si}-18.2\left(\right.$ red. $\left.400^{\circ} \mathrm{C}\right)$ & 244 & 0.27 \\
$\mathrm{NiCu} / \mathrm{SiO}_{2}(500)$ & $\mathrm{Ni}-56 ; \mathrm{Cu}-8.2 ; \mathrm{Si}-18.2\left(\right.$ red. $\left.500^{\circ} \mathrm{C}\right)$ & 175 & 0.21 \\
$\mathrm{NiCuMo} / \mathrm{SiO}_{2} 20$ & $\mathrm{Ni}-46 ; \mathrm{Cu}-6.7 ; \mathrm{Mo}-11.7 ; \mathrm{Si}-15$ & & \\
& $\mathrm{Mo} \times 100 /(\mathrm{Mo}+\mathrm{Ni})=20$ & & 0.22 \\
$\mathrm{NiCuMo} / \mathrm{SiO}_{2} 30$ & $\mathrm{Ni}-41 ; \mathrm{Cu}-6 ; \mathrm{Mo}-17.8 ; \mathrm{Si}-13.3$ & 104 & \\
& $\mathrm{Mo} \times 100 /(\mathrm{Mo}+\mathrm{Ni})=30$ & & \\
\hline
\end{tabular}

In the absence of catalysts the conversion of supercritical ethanol and butanol is not observed to a temperature of $300{ }^{\circ} \mathrm{C}$ [53]. However, at these conditions the Ni-containing catalysts intensify the conversion of butanol, ethanol and organosolv lignins.

In conversion of acetone-lignin in supercritical butanol at temperature $300^{\circ} \mathrm{C}$ the maximum total yield of liquid products isolated by hexane, acetone and diethyl ether ( $90 \mathrm{wt} \%)$ is observed for catalyst $\mathrm{NiCuMo} / \mathrm{SiO}_{2}$ (30) (Fig. 12)

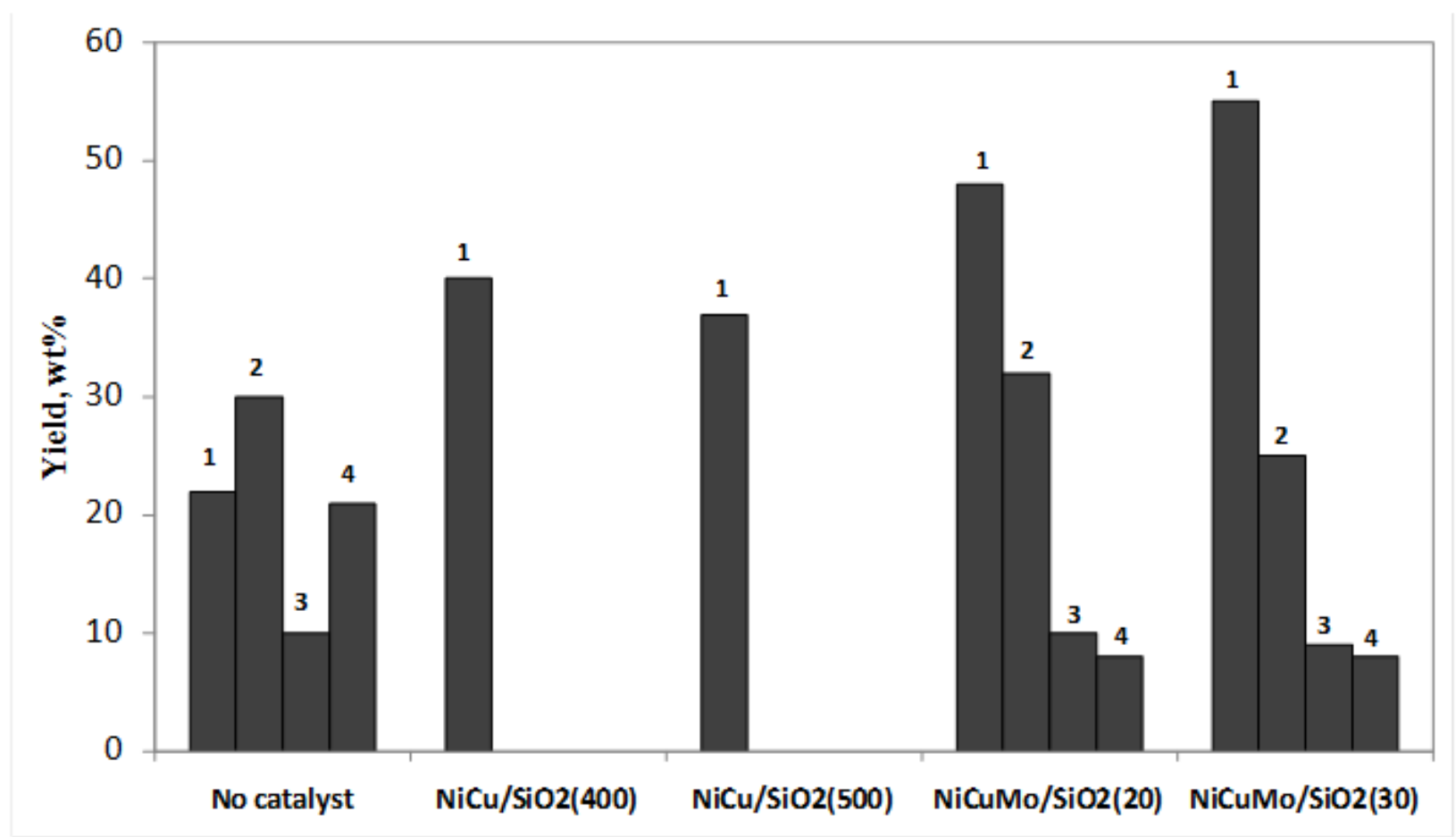

Fig. 12. Yield of products obtained by acetone-lignin conversions over Ni-containing catalysts in supercritical butanol at $300^{\circ} \mathrm{C}$ and $5.0 \mathrm{MPa}$ (wt. ratio wood/catalyst 10:1)

1 - products soluble in hexane; 2 - in acetone; 3 - in diethyl ether; 4 - solid product. 
This catalyst was used to study the thermal conversion of ethanol-lignin in supercritical ethanol (Fig. 13). The catalyst $\mathrm{NiCuMo} / \mathrm{SiO}_{2}$ increases both the conversion of ethanol-lignin and the yield of liquid products soluble in benzene (Fig. 13).

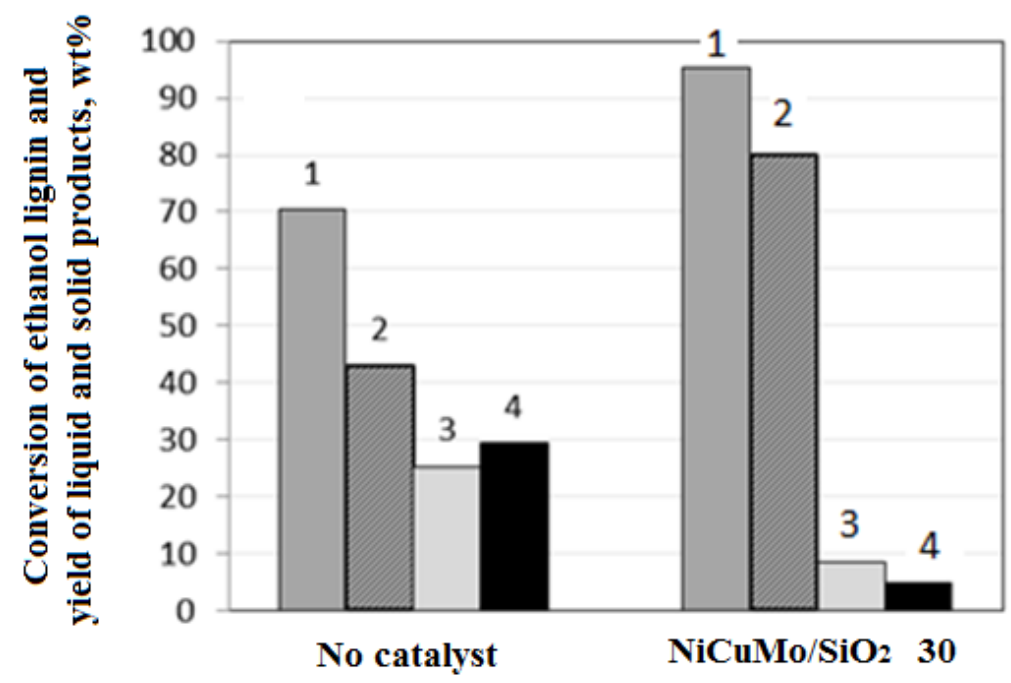

Fig. 13. Influence of catalyst $\mathrm{NiCuMo} / \mathrm{SiO}_{2}$ on the conversion of ethanol-lignin in supercritical ethanol and on the yield of liquid and solid products at $300^{\circ} \mathrm{C}, 11.6 \mathrm{MPa}$ :

1 - conversion; 2 - products soluble in benzene; 3 - products soluble in ethanol; 4 - solid product.

The total yield of liquid products of acetone-lignin conversion in supercritical butanol and of ethanol-lignin conversion in supercritical ethanol reaches to $90 \mathrm{wt} \%$. Catalyst $\mathrm{NiCuMo} / \mathrm{SiO}_{2}$ influences significantly on the composition of liquid products obtained by lignin conversion in supercritical alcohols at $300{ }^{\circ} \mathrm{C}$. It reduces the content of phenol and benzene derivatives and increases the content of esters, aldehydes and ketons in hexane-soluble products.

\subsubsection{Green catalytic biorefinery of wood}

Presented examples demonstrate the feasibility of obtaining the valuable chemicals with rather high yields by catalytic depolymerization of the native and organosolv lignins with solid catalysts and green reagents.

Solid catalysts $\left(\mathrm{TiO}_{2}, \mathrm{NiCuMo} / \mathrm{SiO}_{2}\right)$, low-toxic reagents $\left(\mathrm{H}_{2} \mathrm{O}_{2}\right.$, acetic acid, ethanol, butanol) and the optimum processes conditions were selected for conversions of wood lignins to water-soluble organic products and liquid hydrocarbons.

The separate processes of wood oxidative catalytic fractionation into MCC and watersoluble products from hemicelluloses and lignin, catalytic depolymerization of lignin in supercritical alcohols to liquid hydrocarbons can be employed for the green biorefinery of wood.

The scheme of green biorefinary of wood with obtaining MCC, organic acids, alcohols and liquid hydrocarbons, based on the use of low-toxic reagents and solid catalysts is suggested (Fig. 14). 


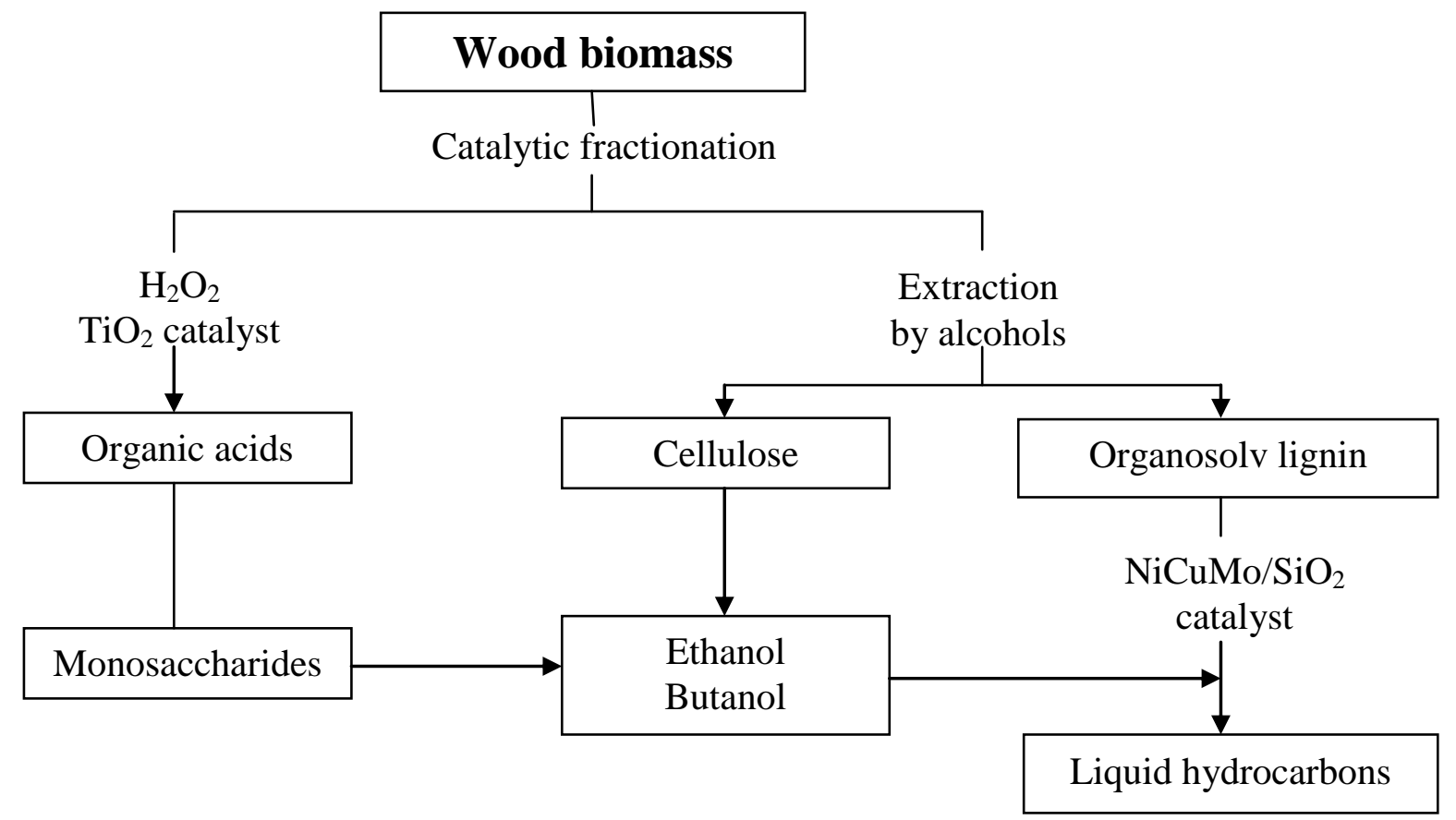

Fig. 14. Scheme of green biorefinery of wood biomass based on the use of low-toxic reagents and solid catalysts.

The integration of studied catalytic processes ensures the environmentally friendly biorefinery of different types of wood sawdust to produce microcrystalline cellulose and a wide range of fine chemicals from lignin and hemicelluloses.

The optimal conditions were found for the processes of peroxide fractionations of hardwood and softwood on MCC and on soluble products from lignin and hemicelluloses in acetic acid - water medium over catalyst $\mathrm{TiO}_{2}$ (rutile) at temperatures $\leq 100{ }^{\circ} \mathrm{C}$ and for organosolv lignins conversion to liquid hydrocarbons over $\mathrm{NiCoMo} / \mathrm{SiO}_{2}$ catalyst in supercritical ethanol or butanol at temperature $300^{\circ} \mathrm{C}$.

The further development of suggested scheme of wood biorefinery should include the use of additional processes of cellulosic product transformation to platform chemicals (5 - HMF, levulinic acid, etc.) and the optimization of composition of soluble organic products for their rational use as fine chemicals and fuel additives.

The more deep study of properties of selected solid catalysts $\left(\mathrm{TiO}_{2}, \mathrm{NiCuMo} / \mathrm{SiO}_{2}\right)$ is needed to demonstrate the possibility of their practical application. The effective solid catalysts for wood biomass oxidative fractionation should be resistant to water and its surface should have optimum hydrophilic-hydrophobic properties. For depolymerization of lignins in hydrocarbon media the solid acidic, metallic and bifunctional catalysts, employed in petrochemical processes can be adapted. 


\section{Conclusion}

The following catalytic processes of native and isolated wood lignins depolymerization are described: the peroxide delignification of hardwood and softwood in the medium of acetic acid - water over $\mathrm{TiO}_{2}$ catalyst and the thermal dissolution of organosolv lignins in supercritical alcohols over solid Ni-containing catalysts.

Catalytic properties of $\mathrm{TiO}_{2}$ samples in anatase and rutile modifications were compared in the processes of aspen wood peroxide delignification at $100{ }^{\circ} \mathrm{C}$. At the same process conditions the use of titanium dioxide catalyst in rutile modification with low surface area (2 $\mathrm{m}^{2} / \mathrm{g}$ ) gives the cellulosic product with lower content of residual lignin and higher cellulose content, as compared to $\mathrm{TiO}_{2}$ in anatase modification with higher surface area $\left(89-11 \mathrm{~m}^{2} / \mathrm{g}\right)$. The reduced catalytic activity of $\mathrm{TiO}_{2}$ anatase can be explained by the following reasons. Probably, the smaller size of pores in anatase samples $(12.4-13.1 \mathrm{~nm})$ as compared to rutile sample (17.9 $\mathrm{nm}$ ) reduces their catalytic activity in wood delignification owing to strengthening of diffusion limitations inside pores. Besides that, a higher concentration of hydrogen groups on the surface of anatase modification of $\mathrm{TiO}_{2}$, as compared to its rutile modification can prevent the formation from $\mathrm{H}_{2} \mathrm{O}_{2}$ the radical species $\left({ }^{\circ} \mathrm{OH}\right.$ and $\left.{ }^{\circ} \mathrm{OOH}\right)$ active in lignin oxidative depolymerization.

The results of kinetic studies and optimization of the processes of peroxide depolymerization of hardwood (aspen, birch) and softwood (abies) lignins in the medium of acetic acid - water over solid $\mathrm{TiO}_{2}$ catalyst at mild conditions $\left(\leq 100^{\circ} \mathrm{C}, 1 \mathrm{MPa}\right)$ are compared. It was found that the increase of temperature, concentrations of $\mathrm{H}_{2} \mathrm{O}_{2}$ and $\mathrm{CH}_{3} \mathrm{COOH}$ in the reaction mixture reduces the yield of cellulosic product and the contents of residual lignin and hemicelluloses in this product.

The catalyst $\mathrm{TiO}_{2}$ initiates the formation of $\mathrm{OH}^{\bullet}$ and $\mathrm{OOH}^{\bullet}$ radicals from $\mathrm{H}_{2} \mathrm{O}_{2}$ which promote the oxidative fragmentation of wood lignin. In this case, the peroxide depolymerization of softwood lignin, constructed from phenylpropane units of guaiacyl-type proceeds more difficult than the hardwood lignins, mainly containing syring-type units.

The yields of cellulosic products obtained from different types of wood under optimized conditions are varied between 48.2-52.6 wt\%. Initial softwood contains more lignin, then hardwood, therefore the higher concentration of hydrogen peroxide $(6 \mathrm{wt} \%)$ is needed for abieswood delignification, as compared to aspen-wood and birch-wood.

The solid and soluble products of wood oxidative delignification over $\mathrm{TiO}_{2}$ (rutile) catalyst at optimized conditions were studied by FTIR, XRD, GC-MS and chemical methods.

The FTIR spectra of cellulosic products from wood and the commercial sample of MCC Vivapur are very similar. All samples have an absorption bands attributed to microcrystalline cellulose. 
According to XRD data the samples of cellulose obtained by peroxide delignification of aspen, birch and abies wood have the structure similar to the commercial MCC. The crystallinity of MCC samples obtained from wood (67-74\%) are close to the crystallinity of industrial MCC.

According to GC-MS data the soluble products of wood peroxide catalytic delignification mainly consist of monosaccharides and of organic acids. Aromatic compounds are present in a low amounts which indicates oxidative degradation of aromatic units of lignin under the used conditions of wood catalytic delignification. The oxidation of benzene rings yields the fumaric, malic, oxypropanoic, $\Upsilon$-hydroxybutanoic acids and of a small amount (6.24 \% rel.) of phydroxybenzoic acid. The reactions of hydrolysis of hemicelluloses and amorphous cellulose give a significant amount of D-glucose (33.91\% rel.) and Xylose (29.80 \% rel.).

The results of the accomplished study demonstrate the possibility of efficient peroxide fractionation of hardwood and softwood at $100^{\circ} \mathrm{V}$ over $\mathrm{TiO}_{2}$ (rutile) catalyst into microcrystalline cellulose and low molecular mass products mainly presented by organic acids and $\mathrm{C}_{6}$ and $\mathrm{C}_{5}-$ monosaccharides.

The results of the study of thermal dissolution of organosolv lignins obtained from aspenwood (ethanol-lignin and acetone-lignin) in supercritical alcohols (ethanol and butanol) over Nicontaining catalyst $\left(\mathrm{NiCu} / \mathrm{SiO}_{2}, \mathrm{NiCuMo} / \mathrm{SiO}_{2}\right)$ are compared.

Data on composition, structure and thermal properties of organosolv lignins were obtained with the use of FTIR, GPC, ${ }^{1} \mathrm{H}-{ }^{13} \mathrm{C}$ HSQC NMR, DTA methods and elemental analysis. According to GPC data the samples of organosolv lignins are characterized by a wide distribution of molecular masses in the range 100-10000 Da. In contrast to ethanol-lignin samples, the acetone-lignin characterized by a single peak ( $700 \mathrm{Da})$ with a low polydispersity index ( 1.5). The comparison of ${ }^{1} \mathrm{H}-{ }^{13} \mathrm{C}$ HSQC NMR spectra of the organosolv lignins shows that the structure of acetone-lignin is more condensed than that of ethanol-lignin.

The influence of a composition of Ni-containing catalyst on the thermal conversion of ethanol-lignin and acetone-lignin in supercritical butanol and ethanol and on the yield of liquid products was established. The highest conversion of lignins in supercritical alcohols (to $93 \mathrm{wt} \%$ ) and the highest yield of liquid products (to $90 \mathrm{wt} \%$ ) were achieved at $300{ }^{\circ} \mathrm{C}$ in the presence of catalyst $\mathrm{NiCuMo} / \mathrm{SiO}_{2} 30$. This catalyst reduces the content of phenol and benzene derivatives and increases the content of esters, aldehydes and ketons in hexane-soluble products obtained from organosolv lignins.

The separate processes of wood oxidative catalytic fractionation into MCC and watersoluble products and catalytic depolymerization of lignin in supercritical alcohols to liquid hydrocarbons can be employed for the green biorefinery of wood. 
The scheme of green biorefinary of wood with obtaining MCC, organic acids, alcohols and liquid hydrocarbons, based on the use of low-toxic reagents and solid catalysts is suggested.

The integration of studied catalytic processes ensures the environmentally friendly biorefinery of different types of wood sawdust to produce microcrystalline cellulose and a wide range of fine chemicals from lignin and hemicelluloses.

\section{Acknowledgements}

The reported study was supported by Russian Science Foundation, grant № 16-13-10326.

This work is a part of GDRI "Biomass" between France and Russia.

\section{Reference}

[1] Von D. Fengel, G. Wegener, Wood. Chemistry, Ultrastructure, Reactions, Berlin 1984.

[2] C. Heitner, D. R. Dimmel, J. A. Schmidt, Lignin and ligans. Advances in Chemistry, CRC Press: Teylor \&Francis Group, 2010.

[3] P. Azadi, O.R. Inderwildi, R. Farnood, D.A. King, Renewable and Sustainable Energy Reviews. 21 (2013) 506-523.

[4] J. Zakzeski, P.C.A. Bruijnincx, A.L. Jongerius, B.M. Weckhuysen, Chem. Rev. 110 (2010) 3552-3599.

[5] R. Ma, Y.Xu, X. Zang, ChemSusChem. 8 (2015) 24-51.

[6] M. Kleinert, T. Barth , Chem. Eng. Technol. 31 (2008) 736-745.

[7] M. Kleinert, T. Barth , Energy-Fuels. 22 (2008). 1371-1379.

[8] X. Huang, T.I. Koranyi, M.D. Boot, E.J.M. Hensen, Chem. Sus. Chem. 7 (8) (2014) 22762288.

[9] T. Ennaert, J. Van Aelst, J. Dijkmans, R. De Clercq, W. Schutyser, M. Dusselier, D. Verboekend, B.F. Sels, Chem. Soc. Rev. 45 (2016) 584-611.

[10] B. Güvenatam, E.H.J. Heeres, E.A. Pidko, E.J.M. Hensen, Catal. Today 259 (2016) 460466.

[11] H. Wang, M. Tucker, Y. Ji , J. of Appl. Chem. 2013 (2013) 9.

[12] S. Van de Vyver, J. Geboers, P.A. Jacobs, B.F. Sels, Chem.Cat.Chem. 3 (2011) 2-99.

[13] P. Maki-Arvela, B. Holbom, T. Salmi, D. Yu. Murzin, Catal. Rev. 49 (2007) 197-340.

[14] S.N. Raveendran, V. Guliants, Appl. Catal., A. 356 (2009) 1-17.

[15] J.Y. Kim, J. Park, H. Hwang, J.K. Kim, K. Song, J.W. Choi, J. Anal. Appl. Pyrolysis. 113 (2015) 99-106.

[16] J. Y. Kim, J. Park, U. J. Kim, J.W. Choi, Energy Fuels. 29 (8) (2015) 5154-5163. 
[17] M.R. Sturgeon, M. H. O’Brien, P.N. Ciesielski, R. Katahira, J.S. Kruger, S.C. Chmely, J. Hamlin, K. Lawrence, G. B. Hunsinger, T.D. Foust, R.M. Baldwin, M. J. Biddy, G.T. Beckham, Green Chem. 16 (2014) 824-835.

[18] Q Song, F. Wang, J. Cai, Y. Wang, J. Zhang, W. Yu, J. Xu, Energy Environ. Sci. 6 (2013) 994-1007.

[19] A.B. Ayusheev, O.P. Taran, I.I. Afinigenova, T.I. Mishchenko, M.V. Shashkov, K.A. Sashkina, V.S. Semeikina, E.V. Parkhomchuk, V.E. Agabekov, V.N. Parmon, J. Sib. Fed. Univ. Chem. 3 (2016) 353-370.

[20] S. Van den Bosch, W. Schutyser, R. Vanholme, T. Drissen, S.F. Koelewijn, T. Renders, B. De Meester, W.J.J. Huijgen, W. Dehaen, C.M. Couurtin, B. Lagrain, W. Boerjan, B.F. Sels, Enegry Eviron Sci. 8 (2015) 1748-1763.

[21] W. Schutyser, Van der Bosch, T. Renders, T. De Boe, S.F. Koelewijn, A. Dewaele, T. Ennaert, O. Vikindereb, B. Goderis, C.M. Courtin, B.F. Sels, Green Chem. 17(2015) 5035-5045.

[22] E.M. Anderson, R. Katahira, M. Reed, M.G. Resch, E.M. Karp, G.T. Beckham, Yu. Roman-Leshkov, ACS Sus. Chem. \& Engineering. 4 (2016) 6940-6950.

[23] B.N. Kuznetsov, V.E. Tarabanko, S.A. Kuznetsova, Kinet. Catal. 49 (2008) 517-526.

[24] B.N. Kuznetsov, I.G. Sudakova, N.V. Garyntseva, L. Djakovitch, C. Pinel, Reac. Kinet. Mech. Cat. 110 (2013) 271-280.

[25] U.V. Karyakin, I.I. Angelov, Pure chemical materials, Chemistry, Moscow, 1974.

[26] M.A. Ermakova, D.Yu. Ermakov, Appl. Catal. A: General. 245(2003) 277-288.

[27] M.V. Bykova, D.Yu. Ermakov, S.A. Khromova, A.A. Smirnov, M.Yu. Lebedev, V.A. Yakovlev, Catal. Today 220-222 (2014) 21-31.

[28] E. Sjoöstroöm, R. Alern, Analytical methods of wood chemistry. Pulping and Papermaking, Springer-Verlag, Berlin, 1999.

[29] J. Quesada-Medina, F.J. López-Cremades, P. Olivares-Carrillo, Bioresource Technology. 101 (2010) 8252-8260.

[30] C. Arato, E. Kendall Pye, G. Gjennestad, The Lignol, Appl. Biochem. Biotech. 1 (2005) $121-124$.

[31] B.N. Kuznetsov, N.V. Chesnokov, O.V. Yatsenkova, V.I. Sharypov, N.V. Garyntseva, N.M. Ivanchenko, V.A. Yakovlev, Wood Sci. Tehnol. 51(2017) 1189-1208.

[32] B.N. Kuznetsov, V.I. Sharypov, N.V. Chesnokov, N.G. Beregotsova, S.V. Baryshnikov, A.V. Lavrenov, A.V. Vosmerikov, V.E. Agabekov, Kinet. Catal. 56 (2015) 434-441.

[33] S. Park S, J.O. Baker, M.E. Himmel, P.A. Parilla, D.K. Jonson, Biotechnol Biofuels 3(2010) 10. 
[34] B.N. Kuznetsov, I.G. Sudakova, N.V. Garyntseva, L. Djakovitch, C. Pinel, Reac. Kinet. Mech. Cat. 120 (1) (2017) 81-94.

[35] C.L. Chen, E.A. Capanema, H.Z. Gracz, J. Agric. Food Chem. 51(2003) 1932-1941.

[36] V. Alves, E. Capanema, Ch-L. Chen, J. Gratzl, J. Mol. Catal. A: Chem. 206 (1-2) (2003) $37-5$.

[37] C. Fernández-Rodrígueza, J.M. Dona-Rodrígueza, O. González-Díaza, I. Secka , D. Zerbani, D. Portillob, J. Perez-Pena, Appl. Catal. B: Environmental. 125 (2012) 383-389.

[38] B.N. Kuznetsov, V.G. Danilov, S.A. Kuznetsova, O.V. Yatsenkova, N.B. Aleksandrova, Theor. Found. Chem. Eng. 43 (2009) 499-503.

[39] A.M. Adel, Z.H. El-Wahab, A.A. Ibrahim, M.T. Al-Shemy, Carbohydr. Polym. 83 (2001) 676-687.

[40] M. Fan, D. Dai, B. Huang, Fourier transform infrared spectroscopy for natural fibres, in Salih S. (Eds.), Fourier transform - material analysis, In Tech, Rejeka, 2012, pp. 45-68.

[41] S. Shankar, J.W. Rhim, Carbohydr. Polym. 148 (2016)18-26.

[42] L.Y.Xiang, M.A.P. Mohammed, A.S. Bahruddin, Carbohydr. Polym. 148 (2016) 11-20.

[43] Y. Nishiyama, P. Langan, H. Chanzy, J. Am. Chem. Soc. 124(31) (2002) 9074-9082.

[44] C. Vailiu-opera, J. Nicoleanu, Polym. Plast. Technol. Eng. 32(3) (1993) 181-214.

[45] C. Crestini, M. Crucianelli, M. Orlandi, R. Saladini, Catal. Today. 156 (2010) 8-22.

[46] B. Saake, R. Lehen, Lignin. Ullmann's Encyclopedia of Industrial Chemistry, Weinheim, Germany: Wiley-VCH Verlas, Gmb\&Co, 2007.

[47] D. Watkins, Md. Nuruddin, M. Hosur, A. Tcherbi-Narteh, Sh. Jeelani, J. Mater. Res.Technol. 4(1) (2015) 26-32.

[48] J. Domínguez-Robles, R. Sánchez, P. Díaz-Carrasco, E. Espinosa, M.T. GarcíaDomínguez, A. Rodríguez, Int. J. Biol. Macromol. 104 (2017) 909-918.

[49] J. Rencoret, G. Marques, A. Gutierrez, L. Nieto, J. I. Santos, J. Jimenez-Barbero, A.T. Martınez, J.C. del R1o, Holzforschung. 63 (2009) 691-698.

[50] J. Zeng, G.L. Helms, X. Gao, S.Chen, J. Agric. Food Chem. 61(46) (2013) 10848-10857.

[51] G. Hu, C. Cateto, Y. Pu, R. Samuel, A.J. Ragauskas, Energy Fuels. 26 (1) (2012) 740-745.

[52] J.L. Wen, Sh. L. Sun, T.Q. Yuan, F. Xu, R.C. Sun, J. Agric. Food Chem. 61 (2013) 11067-11075.

[53] N.G. Beregovtsova, V.I. Sharypov, S.V. Baryshnikov, L.I. Grishechko, A.V. Vos'merikov,B.N. Kuznetsov, J. Sib. Fed. Univ. Chem. 7(2) (2014) 242-251. 